Article

\title{
Evolving the Evolving: Infrastructure, Place and Rewilding in the California Delta
}

\author{
Brett Milligan ${ }^{1, *}$ and Alejo Kraus-Polk ${ }^{2}$ \\ ${ }^{1}$ Department of Human Ecology, Landscape Architecture, University of California Davis, Davis, CA 95616, USA; \\ E-Mail: bmilligan@ucdavis.edu \\ ${ }^{2}$ Geography Graduate Group, University of California Davis, Davis, CA 95616, USA; E-Mail: akrauspolk@ucdavis.edu \\ * Corresponding author
}

Submitted: 29 April 2017 | Accepted: 7 September 2017 | Published: 27 October 2017

\begin{abstract}
Current planning and legislation in California's Sacramento-San Joaquin Delta call for the large-scale ecological restoration of aquatic and terrestrial habitats. These ecological mandates have emerged in response to the region's infrastructural transformation and the Delta's predominant use as the central logistical hub in the state's vast water conveyance network. Restoration is an attempt to recover what was externalized by the logic and abstractions of this logistical infrastructure. However, based on findings from our research, which examined how people are using restored and naturalized landscapes in the Delta and how these landscapes are currently planned for, we argue that as mitigatory response, restoration planning continues some of the same spatial abstractions and inequities by failing to account for the Delta as an urbanized, cultural and unique place. In interpreting how these conditions have come to be, we give attention to a pluralistic landscape approach and a coevolutionary reading of planning, policy, science and landscapes to discuss the conservation challenges presented by "Delta as an Evolving Place". We suggest that for rewilding efforts to be successful in the Delta, a range of proactive, opportunistic, grounded and participatory tactics will be required to shift towards a more socio-ecological approach.
\end{abstract}

\section{Keywords}

California Delta; coevolution; complexity; conservation; infrastructure; landscape approach; logistics landscape; place; scenario planning; water

Issue

This article is part of the issue "Social Ecology of Sustainability", edited by Stephen Wheeler (University of California, Davis, USA), Christina Rosan (Temple University, USA) and Bjoern Hagen (Arizona State University, USA).

(C) 2017 by the authors; licensee Cogitatio (Lisbon, Portugal). This article is licensed under a Creative Commons Attribution 4.0 International License (CC BY).

\section{Introduction}

Current legislation and state plans for the California's Sacramento-San Joaquin Delta (Delta) call for largescale ecological restoration, which will require significant changes in current land uses and cultural patterns (Figures 1 and 2). Restoration mandates in the Delta are heavily driven by the detrimental effects of water exports and the reengineering of the Delta as logistical infrastructure for its conveyance. Our research project, The Human Use of Restored and Naturalized Delta Landscapes, examined how human presence and uses can and will continue after restoration, and considered how these uses could be reconciled with ecological and adaptive management goals (Milligan \& Kraus-Polk, 2016, 2017). The main finding from that research that we selectively focus on in this article is the lack of effective planning and consideration of socio-cultural and place-based values within this transformative effort. Utilizing a pluralistic and co-evolutionary landscape approach, we suggest how this situation has come to be, introduce the predominant challenges faced, and discuss potential solutions and strategies for working effectively with the Delta as a rapidly evolving place. Broadly, we ask: how might ur- 
ban environmental planning in this contested and complex region best lead toward socially transformative ecological recovery?

\subsection{The Delta}

The Delta is a cultural landscape that humans have inhabited and modified for up to 4,300 years in tandem with its ecogeomorphic formation (Pierce, 1988). During the last four millennia of the Holocene, as glaciers retreated and sea levels rose, the Delta began to assume its deltaic and estuarine features, and human communities adapted to these changes, modifying the landscape to meet their needs. This feedback loop exerted pressures, determining future possibilities of socio-ecological systems (SES). Post-contact adaptations and modifications built upon this coevolution. Beginning with the passage of the Federal Swampland Act of 1850, the concerted work of "reclamation" eliminated the complex web of sloughs and seasonal wetlands that characterized the Delta, replacing them with fewer, straighter and much deeper channels running through manufactured agricultural land

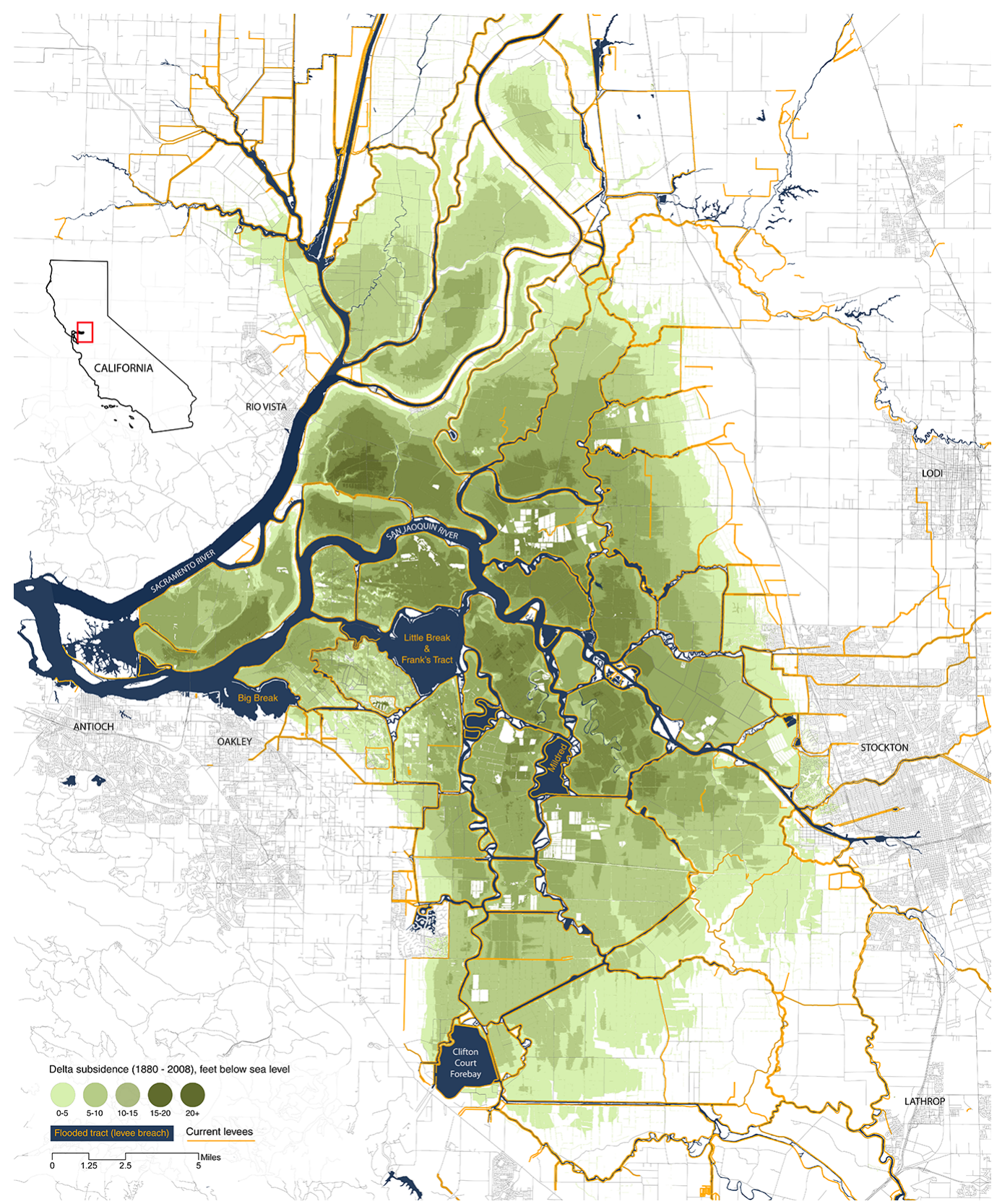

Figure 1. Delta levees, subsidence, and urbanization: once exposed to air through reclamation and the construction of an extensive network of levees (over 1,100 miles), the Delta's peat soils have oxidized and subsided up to 30 feet below sea level, which in turn places greater stress on levees. The Delta is surrounded and encroached upon by expanding urbanization from multiple cities and population centers (Data generated by 2008 Lidar from the California Department of Water Resources). Map by Brett Milligan. 
(Robinson et al., 2014). An extensive network of engineered levees prevents waterways and floods from migrating across the former massive floodplain of the Delta (except when they fail). These alterations radically transformed the Delta, eradicating 95-98\% of dynamic wetland and riparian habitats (Robinson et al., 2014).

In turn, this reclamation infrastructure of dredged channels and levees was conscripted in the latter half of the twentieth century to serve as the central logistical hub in California's State and Federal water projects, a controversial role it plays to this day with respect to ecological, infrastructural and socio-political crisis. One could say that there is no problem in the Delta, rather there are multiple interrelated complex problems, which suggest multiple or unknown solution paths (Rittel \& Webber, 1973). Following Rittel and Webber, planners, scientists and others working in the Delta have described it as a wicked problem (Luoma, Dahm, Healey, \& Moore, 2015; Shigley, 2012).

If the problem were just about allocating freshwater flows, it might be solvable. Add in the complexity of moving water through a hydrologically and hydrodynamically complex Delta and it becomes complicated. Add the uncertainty of ecological responses and the institutional complexity of many actors with many visions and the problem becomes wicked. Then add the ever-changing water supply and ecological and economic contexts within which decisions must be made, and the problem becomes devilishly wicked (Luoma et al., 2015).

Adding to these problems is the vulnerability of the levee infrastructure itself, which is subject to sudden failure due to floods and seismic events, or the slower, increasing threat posed by rising sea level surrounding heavily subsided islands as much as thirty feet below sea level (Deverel et al., 2016; Deverel \& Leighton, 2010; Mount \& Twiss, 2005). The contemporary Delta is an anthropogenic landscape. Human engineering and colonization has moved it "beyond recognition and resulted in irrevocable impacts" (Renaud et al., 2013; van Staveren \& van Tatenhove, 2016). Sparsely populated and pastoral, the legal Delta is often considered a rural place (Thompson, 1957). Yet in terms of systematic land alteration and its infrastructural role in maintaining a globalized economy and cities, the Delta is thoroughly urbanized (Brenner \& Schmid, 2015). The ring of urban centers surrounding the Delta keeps encroaching into it through various forms of development within the floodplain (Norgaard, Kallis, \& Kiparsky, 2009; Shigley, 2012). The resultant landscape is both a novel ecosystem and culturally enigmatic and it is within this urbanized "hydraulic society" (Worster, 1982, 1985) that ecological restoration occurs. These conditions, found both here and in other urbanized deltas around the world, will require recalibration of hydraulic and infrastructural interventions received from the past to "long-term sustainable delta pathways" (van
Staveren \& van Tatenhove, 2016); pathways that consider the complex interaction of environmental dynamics, technology, and socio-political processes.

\subsection{Current Conflicts and Planning Challenges}

The Delta of today is, to greater and lesser degrees, a product of planning. Over the last 150 years, local plans have been eclipsed by state plans, which were in turn warily usurped by Federal plans as the scope, scale and controversies of its planning arenas have expanded. Today, no single entity is in charge (Shigley, 2012). Current collaborative and cross scalar planning processes include local, regional, state and Federal agencies whose primary planning concern for the present and future Delta is where, and how much export of Delta waters should occur for urban and agricultural uses (Lund, Hanak, Fleenor, Bennett, \& Howitt, 2010).

Given the compound infrastructural character of the Delta, meaning the wholesale remaking of it through infrastructural means (dredging and levee building), followed by the "reclaiming" of that infrastructure to serve a larger globalized constituency as the state's water delivery hub, we can confidently describe the Delta as an infrastructural landscape. More specifically, it is a space of flows (Castells, 2001); an emerging breed of neoliberal "logistics landscapes" with "distribution and delivery" of water as its primary function (Waldheim \& Berger, 2008). As Waldheim, Berger and others note, the contemporary expansion of infrastructural and logistics landscapes has given rise to some of the most significant transformations and systemic spread of urbanized and globally networked environments, which often exhibit social and ecological disparities (Brenner \& Schmid, 2015; Graham \& Marvin, 2001; Lyster, 2016; Waldheim \& Berger, 2008). In the Delta, the "rule" or "disposition" of logistics (Easterling, 2014; LeCavalier, 2016) has manifested as the globalized agricultural economy of California's Southern San Joaquin Valley and facilitated the rise of the San Francisco Bay Area and Southern California's metropolises. Within this "deadly life of logistics" (Cowen, 2014) we see the near total ecological transformation of the Delta (Robinson et al. 2014; Wiens, Grenier, Grossinger, \& Healey, 2016).

Logistical landscapes operate on an abstract and economic math of distribution and delivery efficiencies. They mediate between abstracted goals-profit margins, movement of commodities - and the physical and material realities of the landscapes they must use and traverse to provide services (Davis, Holmes, \& Milligan, 2015). This creates inherent friction, as landscapes exceed and impinge upon those economic abstractions through social, cultural and ecological parameters that are not accounted for in logistics' math (Davis et al., 2015). In the Delta this friction manifests in multiple ways. The most obvious are the precipitous decline in Delta native fishes, fisheries and other species as a result of water exports, resulting in an ecological crisis or "regime shift" (Laćan 
\& Resh, 2016; Moyle et al., 2012). Since the 1980s, this has defined a much publicized and polarized controversy of "fish vs. farms". Biological opinions and scientific mandates now place restrictions on when and how much water can be pumped out of the Delta based on state and Federal endangered species act (ESA) criteria.

To reconcile these competing interests, the state has established the "coequal goals" of water reliabil- ity and ecosystem recovery (CA Water Code §85054), which it is aggressively pursuing through "California Waterfix" and "EcoRestore". Waterfix is a massive infrastructural retrofit to the state's water delivery projects, which would construct two 40 feet diameter tunnels to convey water thirty miles 150 feet beneath the Delta, rather than through it (California Natural Resources Agency [CNRA], 2017). EcoRestore (Figure 2) is a plan to fast track the

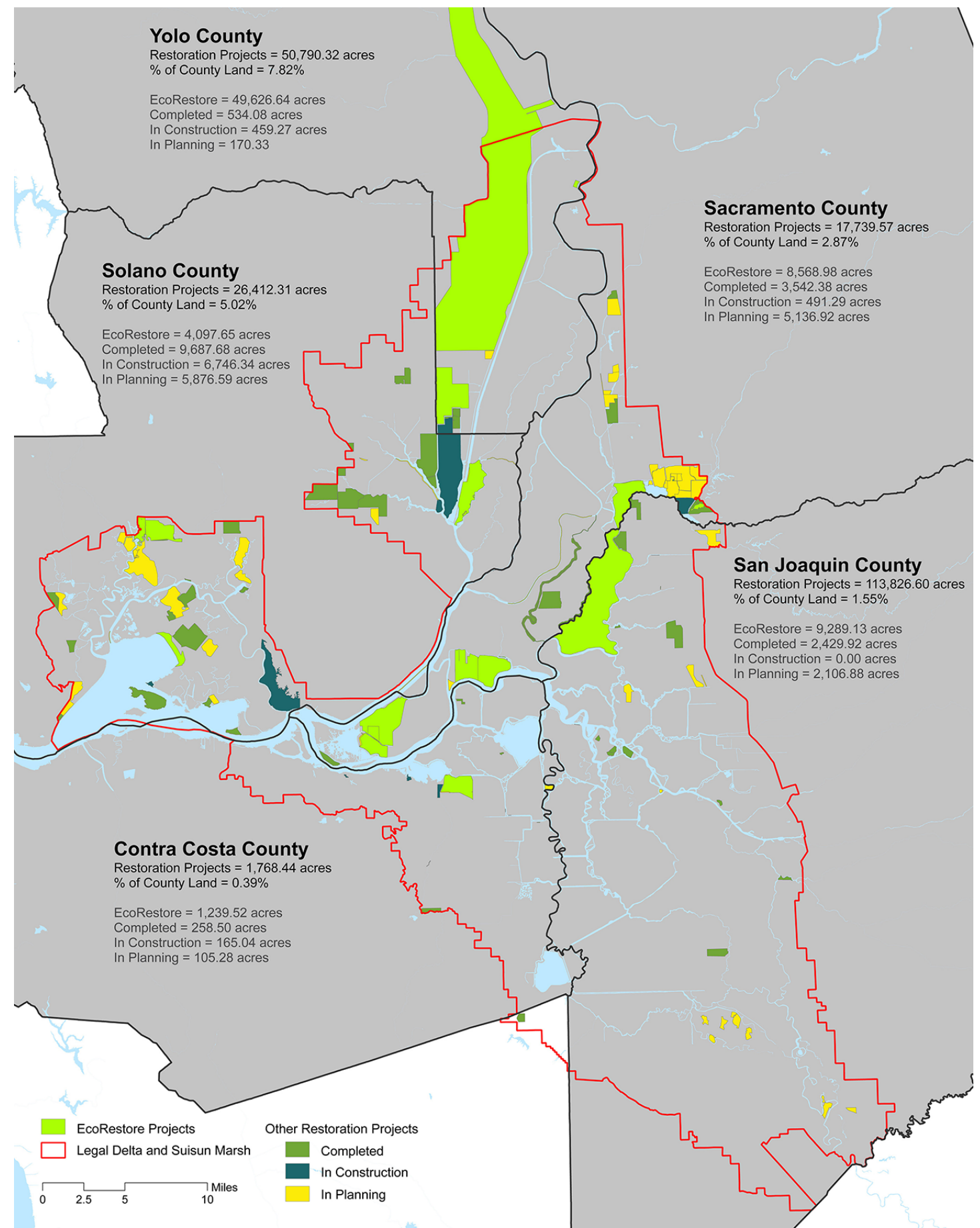

Figure 2. Restored landscapes in the California Delta: current and planned, as of 2016. Map shows proposed EcoRestore projects and all other restoration projects that are completed, in progress or in planning. Total acreages within the Delta are divided up by county. Data from the California Department of Water Resources and EcoAtlas. Map by Brett Milligan and Prashant Hedao. 
restoration of over 30,000 acres of habitat as mitigation for infrastructural side effects described above (CNRA, 2017). Within these plans is a continuation of abstractions, a "scientization" (Laćan \& Resh, 2016; Sarewitz, 2004) that is largely blind to the local and cultural realities of what restoration and ecological land conversion actually entails in the Delta as a dynamic, cultural place subsumed within global logistics. This is the focus of our research.

\subsection{Restoration and Human Uses}

Given the imminent expansion of restored and naturalized landscapes in the Delta, our research investigated how such landscapes are used, occupied and culturally valued, as well as how they are planned for. In a year of empirical study of in the Delta, we found that human uses of these lands are widespread, plentiful and highly diverse. These landscapes consist of waterways, levees, and tracts (reclaimed lands similar to polders in the Netherlands) (Milligan \& Kraus-Polk, 2016). We make a distinction between naturalized landscapes or those which have been unintentionally rewilded, often by a levee breach that went unrepaired (Figures 3 and 4) and restored landscapes, areas where the transition to environmental habitat for other species and ecosystem services is intentional and laboriously designed. This distinction serves to emphasize how human activity arises in these environments, as planned or unplanned, sanctioned or unsanctioned. Human uses range from land management, to scientific research and monitoring, to recreation, to a variety of unsanctioned uses and law

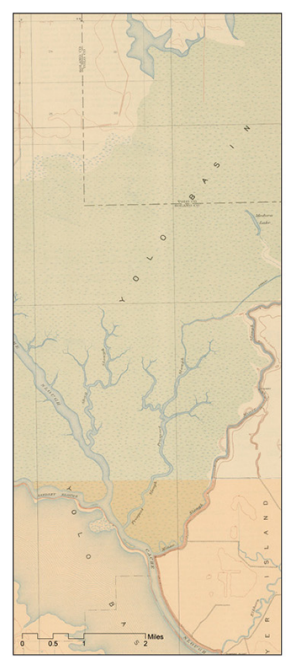

1900s

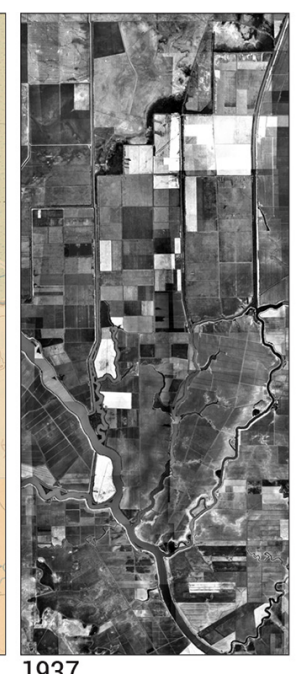

1937

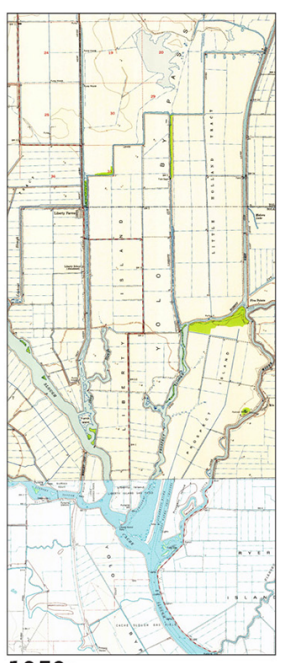

1950s

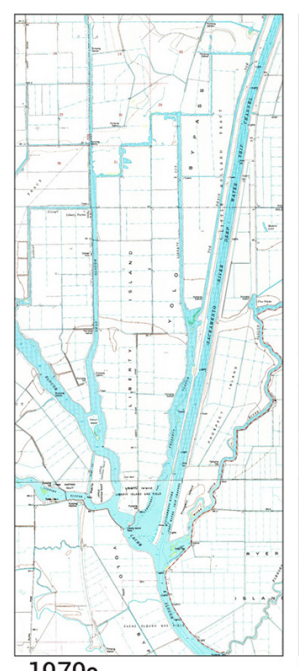

1970 s

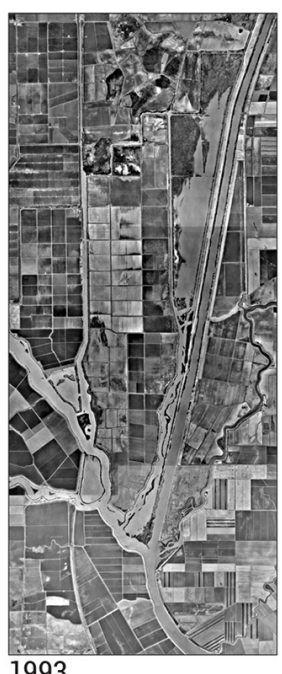

1993

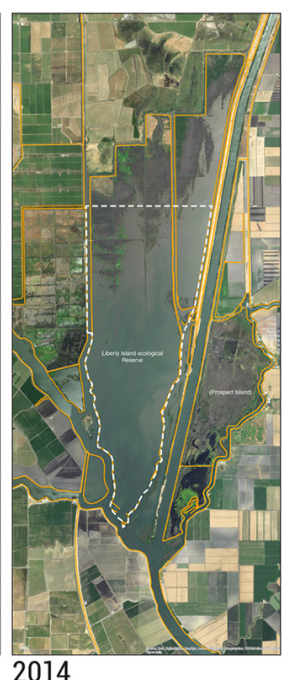

2014

Figure 3. Evolution of the North Delta and Liberty Island: 1900-2014. The sequential series of maps show Liberty Island and the North Delta's transformation from marshland and sloughs, to reclaimed agricultural fields, to the dredging of the Sacramento Deep Water Shipping channel, to re-naturalized landscape "reclaimed" as an ecological reserve. Historic survey data and 1937 ortho imagery from the San Francisco Estuary Institute. Image by Brett Milligan.

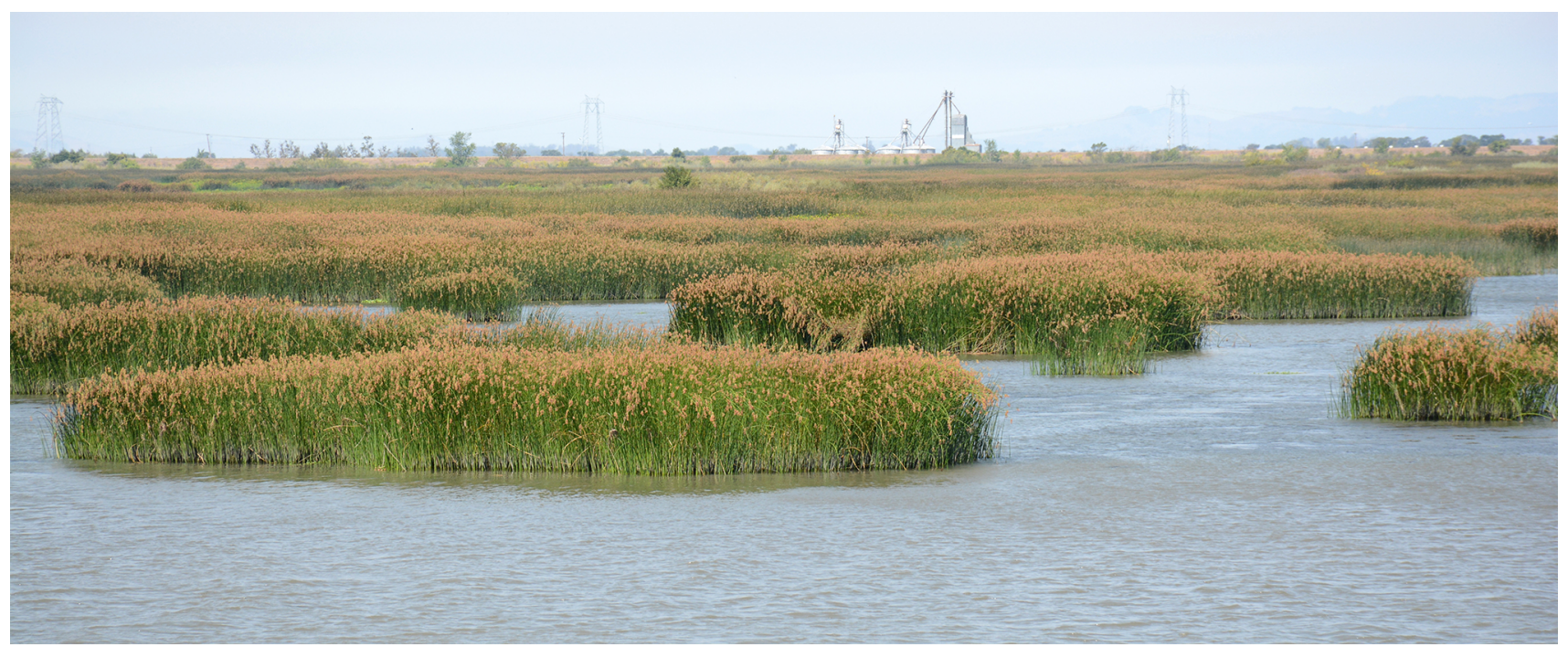

Figure 4. Ground view of tidal marsh formation on what was formerly the Liberty Island Tract, 2015. Prior to a final levee breach in 1997, all of this naturalized landscape was farmland. Image by Brett Milligan. 
enforcement efforts. We encountered situations where human uses are perceived as compatible and beneficial to restoration efforts and others where uses conflict with management efforts and ecological performance. In most cases, a range of specific contextual factors could be identified as contributing to these conditions, including management and planning decisions.

Despite what we found in the field, talking with land managers, law enforcement personnel, and scientific researchers, most Delta restoration planning literature lacks depth and consideration of human uses of these landscapes, or avoids Delta cultural concerns alltogether, given the mitigatory and regulatory basis of the work. Based on our findings, this is a culturally and socioecologically unrealistic approach. Many past efforts at ecological land transformation in the Delta have experienced limited success due to compartmentalized planning approaches that separate the ecological, the social and the technological, when in fact all of these complex and interconnected strands need to be considered cohesively within infrastructural landscapes (Grabowski et al., 2017).

In the following sections, we outline our approach and methods for engaging with socio-ecological complexity in infrastructural landscapes like the Delta. We deploy a pluralistic and coevolutionary method of understanding Delta planning, policy, science and landscapes to specifically explain how ecological restoration is performed to shed light on why "Delta as an Evolving Place" - the official legislative title and mandate bestowed on the region-has remained elusive and marginalized in planning at nearly all scales. Based on our empirical research findings, we take Delta as Evolving Place head on; defining three pervasive challenges it presents to the transformative goals of rewilding an urbanized Delta. We close with discussing planning and design strategies that show promise in working with these challenges.

\section{Approach}

Given the uncertainty, complexity and accelerated change that characterize the Delta, reductive and sectoral approaches to understanding it are less than useful. A multitude of competing factors and actor networks are implicated in the evolution and current status of restoration in the Delta. Thus we subscribe to the need for more pluralistic, pragmatic and expanded epistemologies for encountering complex, evolving phenomena (Mitchell, 2009). Pluralism entails the "integration of multiple explanations and models at many levels [and scales] of analysis instead of always expecting a single, bottom-level reductive explanation" (Mitchell, 2009, p. 113). In this way pragmatism replaces absolutism, recognizing that there are many ways to "accurately, if partially" represent and interpret reality, each with its own values, specificities, and levels of abstraction (Mitchell, 2009). Different disciplines, epistemologies and the world itself organizes in a plurality of context-specific ways, and our knowledge should strive to integrate that diversity (Bennett \& Zurek, 2006). This is not meant to imply that methodologically "anything goes", rather pragmatic pluralism serves as a basis for comparative evaluation of approach and methods according to how well they address specific concerns. A pragmatic approach to inquiry is one that is cognizant of the particular interests and goals it is trying to achieve, knowing that the methods and knowledge gained are themselves provisional, dynamic, value-laden, and evolving through practice and feedback.

Our pragmatic approach draws from two modes of pluralistic explanation, the landscape approach and coevolution. Landscape approaches can be defined as transdisciplinary planning frameworks that seek to integrate multiple competing land uses, with the goal of creating more equitable, adaptable and multifunctional landscapes (Milligan \& Kraus Polk, 2017; Reed, Deakin, \& Sunderland, 2015). Landscape approaches have emerged in response to the inadequacy of single sectoral approaches to planning that fail to accommodate a diversity of stakeholder perspectives. Generally speaking, landscape approaches tend to assess what currently is (such as policies, economic regimes, competing uses and perspectives) as a basis for action and reconciliation. Coevolution is also a multifaceted approach, but in contrast, gives more attention to how such composite conditions have come to be. Coevolution implies that evolving (changing) structures and things mutually influence the evolution of each other, rather than transforming in isolation (Norgaard \& Kallis, 2011). Coevolution is propelled by feedback loops that become selection pressures that provoke adaption from other systems and assemblages, which include the political, cultural, economic and biogeophysical (Gerrits \& Teisman, 2016). Coevolutionary approaches to planning have received growing attention (Boelens \& de Roo, 2016; Gerrits, 2010; Gerrits \& Teisman, 2016; Mees, Tempels, Crabbé, \& Boelens, 2016; Rydin, 2014; Schipper \& Gerrits, 2014; Tempels \& Hartmann, 2014), building off of the work of Richard Norgaard (Gual \& Norgaard, 2010; Norgaard, 1984, 1988, 1994). Specifically, the Delta's recent history can be seen as a "coevolutionary process between science, governance and ecosystems" (Norgaard et al., 2009). Under such an understanding, humans-including plannersare not simply ecological "stressors" or "externalized beneficiaries of the ecosystem's services" (Ogden, 2011, p. 4); rather humans are integral to the design, habitation and evolution of what these landscapes are and will become. A coevolutionary planning approach can be particularly useful in the Delta, which clearly exhibits path dependencies, feedbacks, mutual adaptation, and reciprocal selection (Gerrits \& Teisman, 2016; Norgaard \& Kallis, 2011).

Generally speaking, both landscape approaches and coevolution posit a relational understanding of spatial change in which planners work under conditions of complexity and spatial agency is indeterminately distributed 
among diverse and changing constituencies, including the more-than-human (Bryant, 2014; Rydin, 2014). Thus in efforts to manifest change, planners "become an integrated part of these specific, ongoing actor networks, and co-evolve with them in order to bend them to more sustainable futures" (Boelens \& de Roo, 2016).

The challenge with complexity, pluralism and coevolution lies in the contradictory ways in which we parse complex and interrelated webs of agency to explain changes, mobilize people, and impel action. This work bounds problems, which goes against the openness of coevolution itself. Norgaard and Kallis suggest that we face this contradiction by making explicit choices about, "what coevolves and how" (2011). In our work we approach landscape and coevolutionary approaches as complementary, together offering a historical framework for understanding current conditions, combined with an instrumental and integrative approach for dealing with current matters of concern (Latour, 2004a). Specifically, we attempt to identify what actors appear to play a predominant or infrastructural role in generating change or stasis in landscapes (Milligan, 2015). By identifying where and how stronger selective agency appears to reside, planning and design may begin the work of guiding these landscape assemblies towards more equitable and inclusive developmental trajectories.

\section{Research Methods}

Our study of human uses of restored and naturalized Delta landscapes utilized and tested a landscape approach that consisted of a unique combination of six overlapping and mutually informing methods (Milligan \& Kraus-Polk, 2017). Consistent with emerging landscape approach literature, this mixed methodology was customized to the specifics of the landscapes and region of study, as well as to our research concerns and goals. These methods included a planning and governance review specific to the Delta, a survey questionnaire, interviews, landscape case studies, GIS mapping, and field work. These methods, how they were applied, and how they collectively led to our results are depicted in the methods diagram shown in Figure 5 . We briefly describe each of these methods below (adapted from Milligan \& Kraus-Polk, 2017).

The planning and governance review served to categorize and distill a complex set of protocols and plans that influence the Delta's rewilded landscapes. Planning infrastructure is dense and prolific in the region, with more than 230 Federal, state and local agencies, institutions and stakeholders defining, envisioning and regulating the Delta (Luoma et al., 2015). Our review covered both current and historic protocols and was vital to understanding how the Delta is officially defined and managed and how those definitions and schemata evolve over time. Generally, this research component provided a background that allowed us to analyze all other applied research methods for their adherence or deviation from these protocols. Given our emphasis in this article, we focus specifically on the results of this method in the following section.

The survey consisted of a standard set of questions that we asked of individuals with direct physical experience in these landscapes. The survey assessed perceptions of human uses and landscape boundary conditions. The approach here was one of landscape ecology but focused on human habitation; investigating patterns of use and occupation across a mosaic of heterogeneous landscapes. We had a total of 35 survey participants, which though relatively small, includes most land managers in the region. Overall response rate was likely less than $30 \%$. However, the exact survey response rate is unknown, given that we enrolled agency and organization leads to voluntarily disseminate the survey to their personnel. A diverse array of landscape types were represented in the survey, including Federal and state lands, regional parks, mitigation banks and other private conservation lands. Respondents included personnel from state and Federal agencies as well as for-profit and nonprofit entities. The survey was conducted between March of 2015 and April of 2016. ${ }^{1}$ See Figure 6 for a sample of survey results.

In addition to the survey, we conducted in-person interviews with land managers, resource enforcement personnel, restoration ecologists, environmental planners, Delta agency staff, and field researchers working in these environments. These voluntary interviews, nearly 50 in total varied in length and content. Unlike the survey, interviews allowed for more flexible and in-depth conversations. Many were conducted in the field during tours of landscape case studies (below), and the interview questions were modified as new information emerged. We also had opportunities to follow up with interviewees later in the study with new questions or to clarify previous information. The interviews helped address questions that emerged in survey results and inconsistencies observed in the planning and governance review. The perspectives gathered from our interviews informed all of our recommendations.

Nine case studies allowed for a detailed, comparative study of existing restored and naturalized landscapes in the Delta. Through them we could examine how sitespecific conditions influence human uses, as well as how official planning, management and law enforcement protocols are implemented and to what effect. Multiple ecosystems and management regimes were deliberately selected, including naturalized open water "lakes", tidal marshes; floodplains, and oak woodlands. Ownership included Federal, state, private and nonprofit, with both single owner and multiple owner partnerships and memorandums of understanding represented. For each case study, we looked closely at how the landscape culturally and ecologically evolved to its current state. Each was assembled through a review of printed and online

\footnotetext{
${ }^{1}$ A full list of all survey questions is available in our report appendices (see Milligan \& Kraus-Polk, 2016).
} 


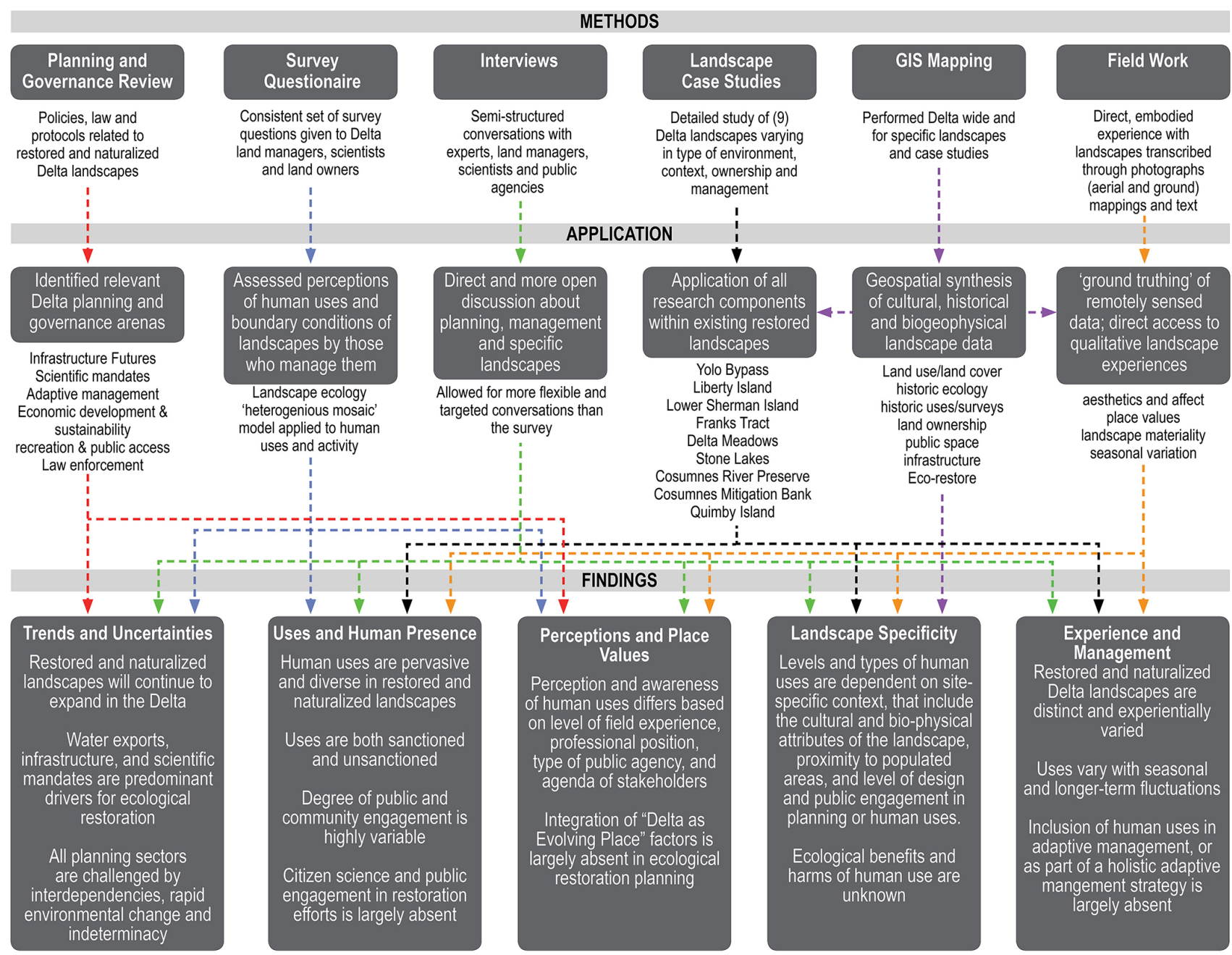

Figure 5. Research Methods Diagram deployed in the Human use of Restored and Naturalized Delta Landscapes study (from Milligan \& Kraus-Polk, 2017). The diagram depicts six different methods, how they were applied and how each method contributed to the study's findings.

resources, participant interviews, extensive field work, on-site photography (both ground and aerial) and GIS mapping. Generally speaking, GIS mapping was used to provide remotely-sensed historical and current geospatial analysis of landscape and ecological transformations (pre- and post-reclamation), shifting ownership and jurisdictions, land use, management, and infrastructure. This was applied to the case studies, as well as to Delta wide spatial analysis (for example see Figure 2).

Field work was essential to "ground truth" the research by offering encounters with the materiality of the environments that we wanted to understand and influence (Rydin, 2014). It included both the interpersonal (micro) and, "macro-influences which trigger transitions, co-evolution and structure-functional change" (Boelens \& de Roo, 2016; Latour, 2004a). Field work consisted of guided tours of landscapes and our own excursions on land and water and was documented through photographs and text. The direct and embodied experience of the field work fed back into the questions we asked during subsequent interviews and augmented the GIS- based mapping of our case study sites. We saw these combined methods as constructing a form of "landscape ethnography" attentive to embodied experiences and relationships with specific places and their temporalities, processes and politics (Ogden, 2011, p. 28).

In our study's report, we detail our findings across each of these research methods (Milligan \& Kraus-Polk, 2016) and provide a more distilled telling of those same results in an open-access article (Milligan \& Kraus-Polk, 2017), demonstrating why we concluded that these landscapes are heavily and diversely used by a wide range of users, with significant desirable and undesirable effects, all of which is not adequately factored into current planning efforts. Given our stated planning emphasis here, in the following section we focus specifically on how restoration planning in the Delta has coevolved with other planning arenas (our planning and governance review) to provide perspective as to why sociocultural concerns and "Delta as Evolving Place" factors have been detrimentally side-lined in these efforts. We then present what we see as the main "Evolving Place" 
Are any sanctioned public uses beneficial to the ecology and functioning of the landscape?
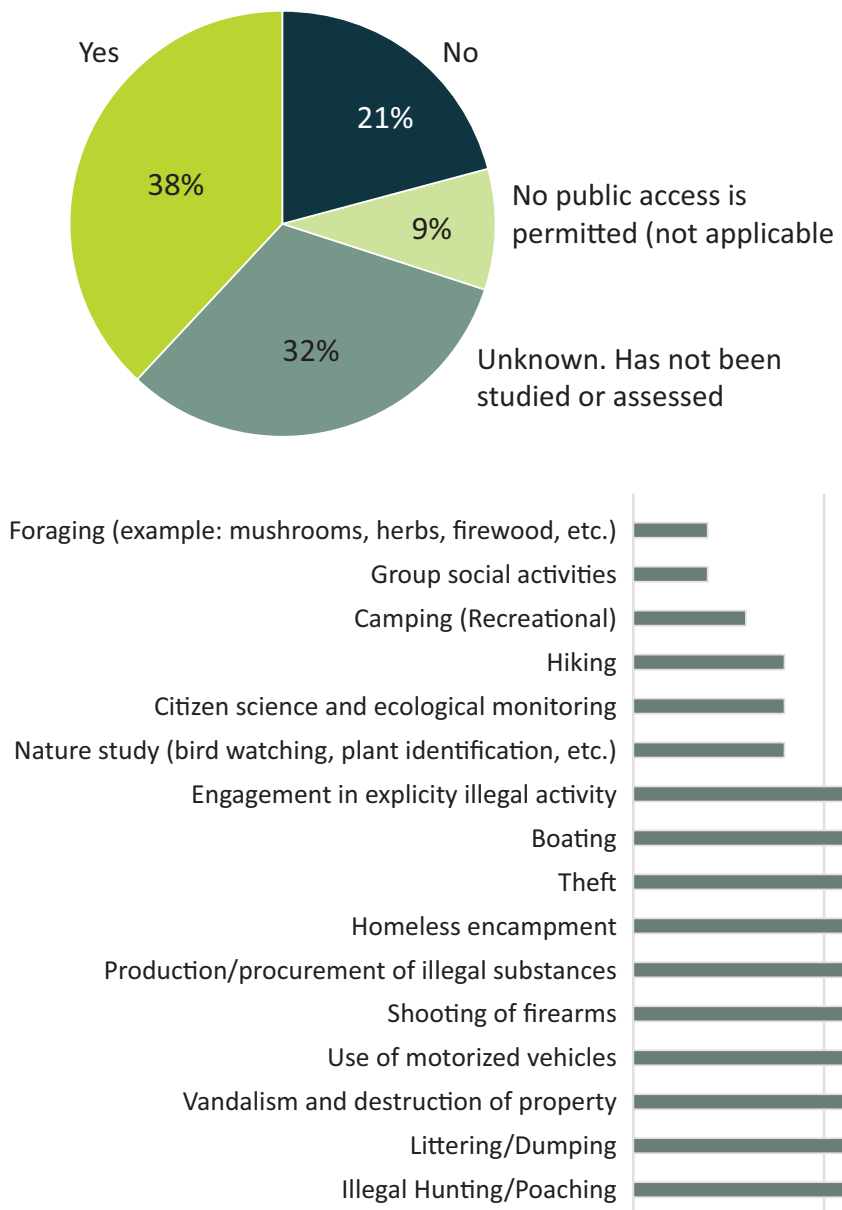

Does unsanctioned human use occur in this landscape?

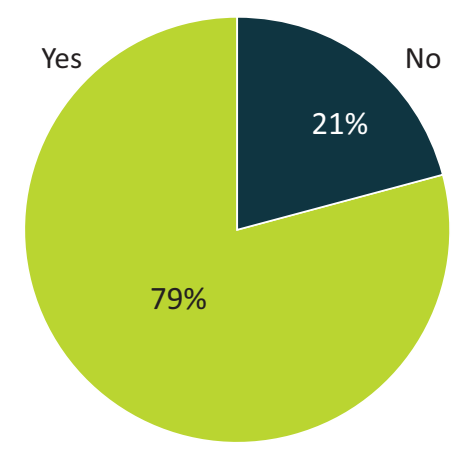

If unsanctioned uses occur on the landscape, what types of activities do they include?

Figure 6. Selection of results from the project survey assessing perceptions of human uses and landscape boundary conditions. The complete survey results are available in the project report (Milligan \& Kraus-Polk, 2016).

challenges that urban environmental planning needs to embrace to be more successful.

\section{Development and Coevolution of Delta Planning}

In the following paragraphs, we describe the coevolving strands of Delta restoration planning as we defined them through our planning review research. Our interpretation of "what coevolves and how" was arrived at through iterative testing, focusing on content, structure, and process (Corbin \& Strauss, 2014; Gerrits \& Teisman, 2016). We applied the mixed research methods described above to the case studies until they consistently addressed the range of contexts, factors and concerns we uncovered. This was a pragmatic approach, recognizing that there can be multiple useful ways to parse the world, with this one customized to our particular concerns (Mitchell, 2009). From this process we arrived at six interrelated planning arenas: 1) Infrastructural Futures, 2) Scientific Mandates 3) Adaptive Management, 4) Eco- nomic Development, 5) Recreation and Public Access, and 6) Law Enforcement (Milligan \& Kraus-Polk, 2017). ${ }^{2}$

\subsection{Infrastructural Futures}

Infrastructure is clearly the predominant matter of concern in Delta planning, as it is the very basis through which the Delta was transformed for settlement and extractive uses, and is the precarious basis on which such future uses depend. The reclamation of the Delta set an evolutionary trajectory that continues into the present. This technological path dependency includes the "reclaiming" of reclamation era levees for water conveyance for the state's massive water delivery projects, which to date remains the primary logistical function and dominant economic use of the Delta. The predominant, pivotal and contested planning question in the Delta concerns how much export of Delta waters should occur, both now and in the future (Lund et al., 2010). The extensive levee network that water deliveries and Delta

\footnotetext{
${ }^{2}$ A more extensive description of these categories is supplied in our reports appendices (Milligan \& Kraus-Polk, 2016).
} 
communities rely upon is subject to failures from earthquakes, rising seas, and funding challenges for maintenance and improvements. Accelerated sea level alone will make through-Delta freshwater conveyance increasingly less feasible. Any changes in levee infrastructure will directly effect what the future Delta will look like and how it will perform in ecological, economic and sociopolitical terms.

The Delta Stewardship Council (DSC) - the lead Delta planning agency established by the 2009 Delta Reform Act-recently completed the Delta Levee Investment Strategy (DLIS) which provided a framework to prioritize the state's levee investments through "combined risk analysis, economics, engineering, and decision-making techniques to identify funding priorities" (DSC, 2017). While the DLIS focuses on flood risk reduction and water supply reliability, there are concurrent mandates that investments also contribute to long-term improvement of river corridors with net benefit for fish and wildlife. The DLIS effort to reconcile the multiple functions of the Delta levees, will indelibly affect the human use of restored and naturalized areas, both quantitatively (how much restored area there is) and qualitatively (what these areas are, such as thickened levees of nebulous accessibility vs. flooded open access tracts).

For water exports, the state's current administration and Department of Water Resources are pushing heavily to move forward on the California WaterFix proposal which would convey diverted water under the Delta in subterranean tunnels for use in the San Joaquin Valley and multiple urban centers. ${ }^{3}$ The sheer length and complexity of this planning proposal render it nearly impenetrable, and perhaps intentionally so. The previous 2013 (BDCP) iteration of this proposal consisted of a 17,000page draft plan and a 22,000-page draft Environmental Impact Report.

Two general conclusions can be drawn about Delta infrastructure planning with respect to restoration. The first is that its future is highly indeterminate. Many plans to alter or sustain these logistical works are uncertain (both in execution, budget, and timeline) and likely to be changed and superseded by new propositions. Given the dominant agency of this planning arena, it renders planning in all others challenging and unpredictable. The second conclusion is that all Delta infrastructural plans for levees and water conveyance-current and proposedwill increase the acreage of restored and rewilded landscapes as required for mitigation of undesirable effects. ${ }^{4}$

\subsection{Scientific Mandates}

Scientific mandates are the primary impetus guiding ecological restoration efforts. Such mandates cover efforts to meet state and Federal regulatory requirements, mitigate for environmental modifications, and adapt to ac- celerated rates of biogeophysical change, including new species assemblages within novel ecologies (Moyle \& Lund, 2015). Scientific mandates for ecological recovery are tightly coupled with the Delta's levee and water export infrastructure, and restoration efforts emerged in direct response to the detrimental effects of diverting and exporting water from the Delta. The loss of native fish populations observed in the 1980s catalyzed the formation of a conservation-oriented "fish-protector" stakeholder group and led to a partnership between state and Federal agencies called the CALFED Bay-Delta Program. CALFED created a fleeting peace by promoting the mantra that "everybody would get better together" (Shigley, 2012), yet ultimately was unable to deal with the underlying contradictions between environmental conservation and continued water-fueled growth (Kallis, Kiparsky, \& Norgaard, 2009). Out of the failure of CALFED came the 2009 Delta Reform Act, which addressed these issues by defining the coequal goals of water supply reliability and protecting, restoring, and enhancing the Delta ecosystem. In theory, the coequal goals place infrastructural and ecological demands on equal footing. But given its institutional evolution, restoration is approached only from a technical and mitigatory perspective, rather than on its own terms or through a broader range of values. Ecological restoration is about meeting state and Federal regulatory requirements in reaction to infrastructural effects.

The concept of "restoration"-a return to some previous historical condition-is problematic in the Delta. Given its radical alteration, it is impossible to reset the Delta to some historic baseline, as it continues to evolve further from those former states at rates faster than many scientists and managers can keep pace. The growing acknowledgement of this ecological uncertainty is leading to new paradigms in Delta conservation, such as reconciliation ecology, defined as, "the science of inventing, establishing and maintaining new habitats to conserve species diversity in places where people live, work or play" (Moyle et al., 2012; Rosenzweig, 2003; Suddeth Grimm \& Lund, 2016). We find these reconciliatory approaches promising for ecological recovery efforts, as they bring the social and cultural back into the ecological, and render scientific value judgments more overt and accessible.

\subsection{Adaptive Management}

Adaptive management is a learning technique that engages with landscape change through adaptive and corrective responses to emergent phenomena (Boelens \& de Roo, 2016). When implemented, adaptive management can help circumvent paralysis in decision-making within contexts of uncertainty (Mitchell, 2009). The Delta Reform Act mandated adaptive management in the Delta, and its incorporation into the recently completed

\footnotetext{
${ }^{3}$ A previous iteration of this project, which entailed a peripheral canal, was rejected by state voters in 1982. Various proposals and propositions have intermittently been in play since that time, leading up to Waterfix.

${ }^{4}$ This assumes the resilience of Federal and State Endangered Species Acts and associated environmental regulation, which has been long under attack.
} 
Delta Plan (DSC, 2013)-the integrative long-term management framework for the Delta. How adaptive management is put into practice in the Delta remains in question, particularly in the integration of efforts across the region and across different forms of science and knowledge making (Delta Independent Science Board [DISB], 2016; Lund \& Moyle, 2013). In our review of "integrative" adaptive management protocols, we definitively observed that human presences and uses were not included, even though nearly all of the land managers and scientific researchers we surveyed or interviewed shared numerous informal stories of how they actively manage sanctioned and unsanctioned human uses (Milligan \& Kraus-Polk, 2016, 2017). We interpreted this as another indication of the compartmentalization of science and restoration planning, since in spite of contact with pervasive social and cultural phenomena of varied effects, more inclusive adaptive protocols have not emerged in response. We speculate that this will likely change in the future, given the sheer magnitude and increasing human presence on these lands.

The three other planning arenas we identifiedDelta Economic Development and Sustainability, Recreation and Public Access, and Law Enforcement-were observed to have far less presence and potency. They were weakly tied to restoration efforts, with the likely effect of diminishing the potential benefits and success of restoration efforts.

\subsection{Economic Development and Sustainability}

Delta economic development planning seeks to bring more visibility, allure and economic activity to the Delta, and with it, more financial sustainability to Delta communities. Major planning efforts include a National Heritage Area (NHA) proposal currently before Congress (Delta Protection Commission [DPC], 2017), a Delta Branding and Marketing Project, the Vision 2030 Strategic Plan (DPC, 2015), and periodically updated Economic Sustainability Plans (DPC, 2012). These plans tend towards assuming the continuation of agricultural production as it is in the Delta, yet this development pathway is threatened by several factors, including accelerated climate change, new water conveyance infrastructure (WaterFix), and national and international commodity volatility. Further, most of these plans focus on agricultural tourism and recreation with little if any attention to the Delta's novel ecologies and the many efforts to redesign, augment and manage them.

\subsection{Recreation and Public Access}

Delta planning protocols "recommend" rather than mandate that agencies provide recreation and public access opportunities in newly restored areas (DSC, 2013). Integrating recreation and public access into restoration and infrastructure projects has proven to be a challenge. Yet plans and efforts by state agencies to increase public access and recreation opportunities in the Delta exist (California Department of Parks and Recreation [CDPR], 2011; DPC, 2017). The Recreation Proposal for the SacramentoSan Joaquin Delta and Suisun Marsh lays out a range of reasons why planning for human use in restored and naturalized landscapes leads to a broad range of socioecological benefits. Whether such plans will be implemented is uncertain (CDPR, 2011).

\subsection{Law Enforcement}

Generally, we found law and resource enforcement issues critical to restoration virtually nonexistent in Delta planning literature. It was mainly through our interviews and conversations with law enforcement personnel that we gained a better understanding of their unique and changing needs. ${ }^{5}$ As restored and naturalized lands expand so will demands for public safety and law and resource enforcement to address poaching, (il)legal marijuana production, vandalism, trespass, dumping, illegal encampment, etc. Resource enforcement is specifically concerned with upholding laws, such as those within the California Public Resource Code, that serve to protect, conserve and manage unique and limited natural resources held in public trust for current and future generations. Planning recommendations are particularly lacking in explicit support for resource enforcement.

Reading across these domains, it is clear that Delta restoration planning has developed in a particular way, as a mitigatory reaction to the mining and export of the state's water on a grand scale. As a well-intentioned effort to bring back what infrastructure has displaced, restoration planning has introduced its own abstractions upon the infrastructural abstractions it intends to counter, such as the setting of restored habitat acreage targets divorced from geographic specificity, mandatory environmental water flow quantities, etc. What infrastructure and restoration have both missed in these layered abstractions is an awareness of Delta as a unique, cultural and urbanized place. Social values and concerns within the greater Delta region (such as the economic, recreational, and law enforcement planning domains we described) have received little attention in these schemata, likely because they are overshadowed by the networked and subjugated infrastructural role the region plays. But specifically for restoration, these "Delta as Evolving Place" factors have a considerable role in whether or not these landscapes will be successfully stewarded and accepted by local communities. Based on our study's findings, in the following section we discuss

\footnotetext{
${ }^{5}$ The law and resource enforcement agencies we talked with included the Delta Bay Enhanced Enforcement Program (DBEEP) and the Marijuana Eradication Task force (MET), both special operations unit of the California Department of Fish and Wildlife's (CDFW) Law Enforcement Division (LED), US Fish and Wildlife Service (USFWS) law enforcement, the Drug Enforcement Administration, Sheriff's offices from all 5 Delta counties, the US Coast Guard (USCG), the High Intensity Drug Trafficking Area Program (HIDTA), and the California Highway Patrol (CHP).
} 
three unique challenges of "Delta as Evolving Place" that conservation efforts are likely to encounter.

\section{Conundrum and Challenges of "Delta as Evolving Place"}

The evolving is the tricky part, isn't it? [The Delta] has to change. It will change because of sea level rise if no other reason and because of continuing drought and possibly super floods from El Niños. Things are going to change. How it changes, whether it is a well thought out incremental program of change where people are convinced to participate, or whether it gets done to people through catastrophe, I don't know...a lot of people just want to see it stay the way it is, and who think the way it is the best way it should be or could be...So what is the nature of the evolution? (Jennifer Ruffolo [formerly with the Delta Protection Commission], research interview, September 2015, Milligan and Kraus-Polk 2016).

The California Delta is a unique and distinctive region, as recognized by the 1992 Delta Protection Act (CA Public Resources Code §29700-29780) the 2009 Delta Reform Act (CA Water Code \$85000-85004) and the Delta Plan (DSC, 2013). As the Delta Protection Act states: "The Delta is a natural resource of statewide, national, and international significance, containing irreplaceable resources, and it is State policy to recognize, preserve, and protect those resources for current and future generations, in a way that protects and enhances the unique values of the Delta as an evolving place" (PRC sections 29701-2). This was further articulated by the Blue Ribbon Task Force and referenced in the Delta Plan:

Protecting the Delta as an evolving place means accepting that change will not stop, but that the fundamental characteristics and values that contribute to the Delta's special qualities and that distinguish it from other places can be preserved and enhanced while accommodating these changes (Delta Vision Blue Ribbon Task Force, 2008). It does not mean that the Delta should be a fortress, a preserve, or a museum.

The ratification of these acts and the adoption of the Delta Plan acknowledge the importance of social and cultural attributes of the Delta in relation to pressing and controversial decisions that will affect the region, including water management and exports, land management and ecological recovery efforts. Yet how "Delta as Evolving Place" is developed, researched and articulated, per these mandates, remains elusive. As the DISB recently stated: "[I]ittle has been established about the unique values of the Sacramento-San Joaquin Delta as an evolving place and the social and environmental processes supporting those values. Research in this area is sorely needed if those values are to be protected and enhanced as decisions are made to meet the co-equal goals of reliable water supplies and restored ecosystems" (2017).

We found this conclusion particularly relevant to restored and naturalized Delta landscapes, where planning seems "freed" from such place concerns. ${ }^{6} \mathrm{Hu}$ man uses-be they scientific, managerial, recreational, or unsanctioned-can significantly affect restoration planning, implementation and metrics of successbeneficially and detrimentally. Distilling our study's findings across interviews, fieldwork, and literature/planning review, we outline three Delta place conditions that we see playing a major role in what the future of the region might be: 1) the highly dynamic nature of the Delta, 2) the Delta's territoriality, and 3) the pleasures and politics of experience. We found that these phenomena have persisted across time and affect all planning arenas, and thus should be considered in socially transformative ecological planning efforts.

\subsection{Accelerated Change: The Delta in the Anthropocene}

The Delta ecosystem of today will not be the Delta ecosystem of tomorrow. The only constant is change, which we are not good at anticipating or embracing. (Moyle \& Lund, 2015)

"Delta as Evolving Place" presents spatial and cultural challenges since the human conception of place depends on consistency over time, a quality that isn't characteristic of the region (Smith, 2013). The Delta's history of transformations and accelerated rates of change has led to a remarkable diversity of place definitions in a relatively short period of time (Center for California Studies, 2015). As part of the interviews we conducted for our study, we asked representatives from a variety of state and Delta agencies how they define "Delta as Evolving Place", or to talk about what it means to them for guiding governance of the Delta. This question was often met with a blank expression, a laugh, a shift to another topic, or a statement about general uncertainty. However, we were sometimes met with a focused effort to articulate an answer. We began this section with Jennifer Ruffolo's (Delta Protection Commission) response to the question, which seems to get at the difficulty and elusiveness of the concept and the thing itself.

Combining "place" with accelerated rates of environmental change that "evolving" entails is not just a legislative conundrum, but also a physical, spatial and political one. Human colonization and wholesale transformation of the Delta has been rapid in social, technological and geographic terms-only over a century in progressand is being played out concurrently in large delta estuaries around the world (Renaud et al., 2013; Tessler et al., 2015; Vörösmarty et al., 2009). Climate change and sea

\footnotetext{
${ }^{6}$ This is despite repeated calls for better integration. The most recent being the November 2016 State of Bay Delta Science Report, which included in their forward thinking actions a recommendation to: “Weave 'Delta as an Evolving Place' into all science, planning and management programs" (DSC, 2016).
} 
level rise in the Delta is a pressing concern, with conservative projections for 2100 ranging from between $0.2 \mathrm{~m}$ and $1.7 \mathrm{~m}$ of additional rise from the end of the 20th century (Dettinger et al., 2016). Regardless of exact rate and magnitude, sea level rise will increase salinity and increase stress on levees, threatening water supplies (Cloern et al., 2011; Dettinger et al., 2016). Tidal wetlands restored today may be drowned, or migrate into upland areas. As Jennifer Ruffolo remarked, the California Delta will continue to rapidly change, whether we want it to or not, due to actions we have already taken.

In working with "Delta as Evolving Place", it may be more useful to think specifically in terms of emplacements and displacements (for both humans and nonhumans) over time, which speaks more specifically to evolutions in form and occupancy (Drenthen, 2009; Ogden, 2011), landscape migration (Milligan, 2015) and the "politics of nature" (Latour, 2004b; Ogden, 2011). In the Delta, the definition of place and its evolution are inherently political, economic and tied to territorial claims. Restoration efforts are one form of deliberate landscape change-an emplacing of a new place and simultaneous displacement of the former-and thus are embedded in this territoriality.

\subsection{Delta as Territory and Perennial Frontier}

Water solutions almost always have both winners and losers. This is obvious in a case like the Delta, where it's simply not possible to find a fix that will make everyone better off. That's because every available option involves tradeoffs in which at least one party doesn't fare as well, whether it's farmers in the Delta, farmers in the San Joaquin Valley, urban residents south of the Delta, or the Delta's native fish and wildlife...As a society, we can aim for solutions that get the most benefits per dollar spent, but we also need to consider how to soften the blow if some groups are disproportionately bearing the costs. (Hanak, 2015)

[W]hen environmental scientists are in charge of the recreation, public access is problematic. So it is easier not to do it. (Cheryl Essex [California State Parks], research interview, July 2015, Milligan and KrausPolk 2016).

In defining the Delta as a territory, we mean it in both the sense of a region with a different status than other parts of the state, as well as in the sense of territoriality-the behavior of trying to keep others away from an area one uses or controls. The Delta suffers from the latter because it is over-allocated, with neither the money, land or water to meet everyone's expectations. As Jane Wolff states, "[t]he range of people who want something from the Delta has grown...their goals for the landscape are different; they understand it in different ways; and they imagine its future differently. The fault lines ${ }^{7}$ among the Delta's constituents are complicated, variable, and sometimes counterintuitive" (Wolff, 2003, p. 40). See Figure 7.

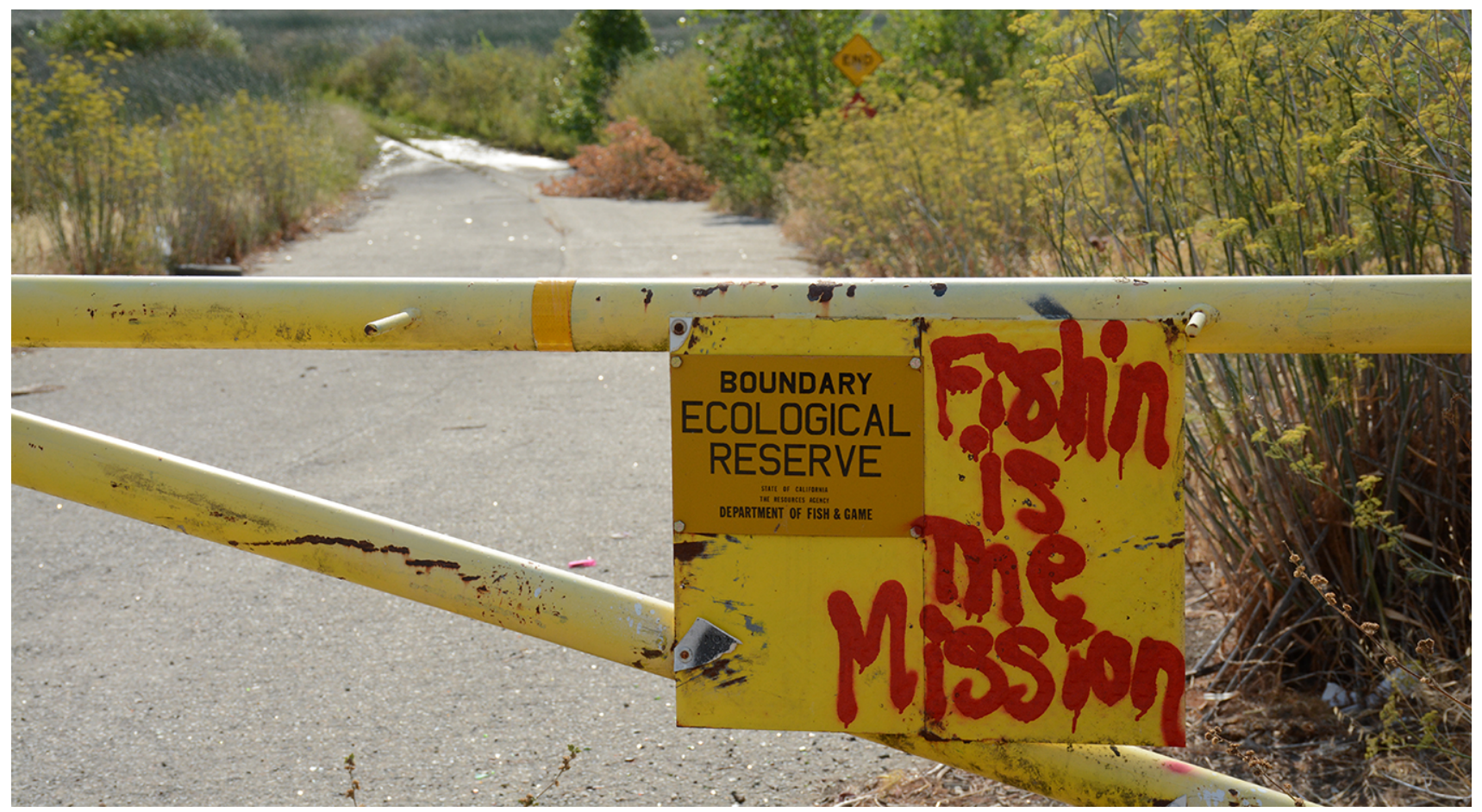

Figure 7. Entrance sign to Liberty Island, Summer 2015, revealing different conceptions and uses of the landscape. Image by Brett Milligan.

\footnotetext{
7 For more on risks associated with seismic activity in Delta see (Mount \& Twiss, 2005). This highly contentious paper catalyzed the formation of the Delta Blue Ribbon Task Force under Schwarzenegger and earned the lead author, Jeffrey Mount, the sobriquet "Dr. Doom".
} 
This territoriality occurs in ecological restoration efforts. Within the scientific discourse, there is great uncertainty and debate regarding the definition and status of the current Delta ecosystem, the past to which it is compared and possible futures of what it might and should become. Many ecologists have become comfortable defining it as a novel ecosystem in which an unprecedented combination of species interact in its highly altered environments with actions that are often irreversible (Hobbs, Moyle, Fangue, \& Connon, 2017; Moyle \& Lund, 2015). Many non-scientists also embrace this novelty; participating in fishing tournaments for the non-native black bass (a major predator of endangered salmon), running bayou-themed eateries, or farming wine grapes beneath levees as ships sail "overhead". Some of the same people are adamant that the Delta cease its unruly changing, and that the state, which has played a fundamental role in its shaping, leave the Delta alone. Desired futures are based in part on select understandings of the past. Much contention stems from tenuous "baselines" used by diverse stakeholders to demarcate preferred and desirable states for the Delta, both wild and urbanized.

Accelerated landscape change combined with heightened territoriality paradoxically render the Delta as a perennial frontier - the dynamic limit of "settled" land. All empirical evidence shows that the Delta has been and will continue to be reoccupied in ephemeral ways, dating back to pre-European contact (Helzer, 2015). The Delta of today cannot be sustained, and our human settlement of it is part of a relatively young, adaptive experiment being carried out in urbanized deltas around the world (Renaud et al., 2013; van Staveren \& van Tatenhove, 2016). As both territory and frontier, there are many prognostications, concerns and controversies regarding how the Delta will be settled, unsettled and rewilded in the near future.

\subsection{Aesthetics, Pleasure and the Politics of Experience}

It is hard to tell people how they can experience wildlife. (Bart McDermott [Stone Lakes National Wildlife Refuge], research interview, October 2015, Milligan and Kraus-Polk 2016).

All types of Delta wilds (restored and naturalized landscapes) are essentially feral, having emerged from a state of domestication and former land uses. Rather than just simply being made, these transitions occur through various practices, whether of action or inaction. How a person experiences and interprets such rewilded landscapes is tied to their life experience and interests. Land managers and scientists working in Delta landscapes experience them differently than a Bay Area resident, who might visit the Delta every couple of years to "dawdle", seeking, "a place of escape, a hideout, a place to drop out of the modern world..." (Helzer, 2015, p. 40).
Compared to the sporadic recreationist, the land manager and the scientist's perceptions of restored or naturalized landscapes are developed through more habitual immersion within the landscape based on specific professional tasks and interests. As observed in our interviews and fieldwork, these habits are diversified, such as monitoring fish populations through sampling and collection, creating elevational surveys of a restored floodplain, and surveying the growth of plants on restoration test plots. They have an embodied and intimate relationship with these landscapes and what occurs within them, which for many, is why they chose this work (Eliason, 2006). ${ }^{8}$ For comparison, consider how qualitatively different these "field" experiences are from that of a GIS mapping technician, or that of a planner's remote media access to these landscapes through technical reports and publications (Boelens \& de Roo, 2016). These qualitative experiences and the knowledge they build are fundamentally different from that developed by living and working in the place itself. Different modes of existence (Latour, 2013) lead to different notions of place and value.

Anthropologist Tim Ingold refers to these "patterns of dwelling activity" as taskscapes (Ingold, 1993, p. 153), which can be a useful way to consider activities within restored and naturalized landscapes in the Delta. A taskscape encompasses the range of activities performed within or upon a landscape, and thus "[t]he activities that comprise the taskscape are unending, the landscape is never complete: neither 'built' nor 'unbuilt', it is perpetually under construction" (Ingold, 1993, p. 162). Taskscapes include everyday life: work and play. Over time, these everyday practices affect and are affected by the landscape medium itself, rendering them inseparable.

In planning and designing for restoration, user experiences matter. Human uses entail presences that enact and create landscapes through diverse practices, protocols, encounters, and desires. In terms of recreation, the Bureau of Reclamation expresses this diversity well: "The average visitor [or user] does not exist" (2011, p. 3). Their statement alludes to the complexities of planning for conventionalized types of outdoor recreation. Defined as what people do for fun and entertainment, recreation is inherently broad, transcending the simplified conventions often ascribed to it. In the Delta, recreation is only one sector among a much broader range of human uses that span the scientific, management practices, and a much broader spectrum of sanctioned and unsanctioned activities. All of these human activities, desires and practices play a role in the perpetual construction of Delta landscapes.

These challenges of "Delta as Evolving Place"accelerated landscape change, territoriality, and diversity of experience and values-will need to be addressed in the planning, designing and managing for Delta Wilds. Suggestions and examples for how ecological recovery efforts might work with the challenges are addressed in the following section.

\footnotetext{
8 This was consistently tested and demonstrated in our interviews.
} 


\section{Recommendations}

Our Human Use of Restored and Naturalized Landscapes research project was focused on understanding how people currently use and occupy these places, and how they are approached and planned for within an infrastructural context. Given the general lack of social and place-based considerations we documented, the next step is to move towards ways of actively changing the status quo to generate more desirable and successful outcomes for people and ecosystems. This will require considerable work to shift from current practices to an approach that is more socio-ecological in orientation and more attuned to local contexts and place-based realities. Although we found that the way in which restoration efforts have emerged in the Delta are specific to its unique context, the minimal funding and priority given to community input, public access and cultural concerns generally in large-scale restoration efforts is a systemic national problem that has broad applicability (Ogden, 2008). In our study's report, we provide a variety of specific and targeted recommendations for improving socio-ecological restoration planning, design and management practices in the Delta, ranging from the local to national scale (Milligan \& Kraus-Polk, 2016). Here we focus more generally on the value of pluralistic methods of interpretation and how urban environmental planning might effectively engage these challenges.

Our first general recommendation concerns how we access, experience and understand complex and conflictual planning environments. Based on our research experience, we advocate for the additional application of pluralistic and pragmatic methods for engaging with "wicked" planning problems. The need to move beyond single discipline or sectoral approaches to planning in these contexts, such as those of landscape planning approaches, is fairly well known. But effective methods for doing so are less developed and would benefit from the additional application and methodological testing (Bennett \& Zurek, 2006). Based on our experimental research experience, a pragmatic and pluralistic approach provides an avenue to get beyond the single problem or solution identification paralysis described by Rittel and Webber (1973) since multi-faceted/perspective approaches do not assume a best entry point. Rather, they encourage an iterative, transdisciplinary learning process subject to refinement through interaction with a range of media, environments and stakeholder perspectives, as accessed through mixed, interrelated methods of encountering them.

Pluralistic methods provide access to what is coevolving with what, and in what ways, through inhabiting, interrogating and moving across these interacting arenas. In this way, "[p]lanners are not so much intervening as drawn into associations which are then the cause of change" (Rydin, 2014). In our experimental study, we found that what we learned across the six overlapping methods was greater than the sum of the components, and far greater than if we had deployed only one or two of the methods. Perhaps most critically, our approach combined distanced analytical methods (i.e. policy and governance review and GIS spatial analysis) with more personal and informal encounters (interviews) and embodied fieldwork (case studies). This allowed for us to see how top-down processes (such as infrastructural plans and scientific mandates) were interacting with bottomup actions and context-specific realities (how people felt about these landscapes and what they were actually doing in them). This provided for a richer and messier understanding of these places that served as a counterpoint to pervasive tendencies toward overly reductive and universal explanations (Mitchell, 2009). This can help to avoid planning's own tendencies for material, social, and ecological abstractions that suppress specific landscape and contextual factors.

Our second recommendation, tied to the first and framed as a question, is how can we foster more adaptive planning within these indeterminate and challenging contexts? Our observations from the Delta (and likely those from elsewhere) suggest that urban environmental planning and its protocols often lag behind identified problems and emerging realities. The need for adaptive management in the Delta and conservation is widely recognized. Similarly, in planning practice, how can we adapt more quickly, responsively and contextually? We have two general suggestions for this: proactive opportunism and exploratory scenario planning.

As we have shown, social and cultural aspects of ecological restoration planning and practice in the Delta (and elsewhere) are typically side-lined, or left out entirely within the logic of infrastructural ambitions and scientization, which in turn leads to less sustainable and less publicly supported restoration. Fostering acceptance and place-based benefits in these efforts will require proactive action that utilizes opportunities as they emerge. This can occur across planning scales, from the project level to state and Federal planning. As an example, the North Delta Flood Control project is a state planning effort to convert a 1,600-acre Delta tract into flood management infrastructure (California Department of Water Resources, 2010). This will be achieved by breaching and modifying the tract's existing levees, which will create new open water areas, tidal marshes and riparian floodplain habitat for a variety of species, including humans. Again, in this instance only the infrastructural and ecological benefits of the project were being considered, even though it will have impacts on adjacent agricultural and urban communities and will be used by people, whether or not they are planned for or are invited into the planning process. This nascent project presented an opportunity to proactively envision a range of additional social and public benefits for the project and for the planning agencies involved, which in turn helped to build public constituency and support (Figure 8).

If the imagination of infrastructural logistics is typically limited to economic abstractions, then planning 


\section{COGITATIO}

Proposed channel and upland habitat contouring
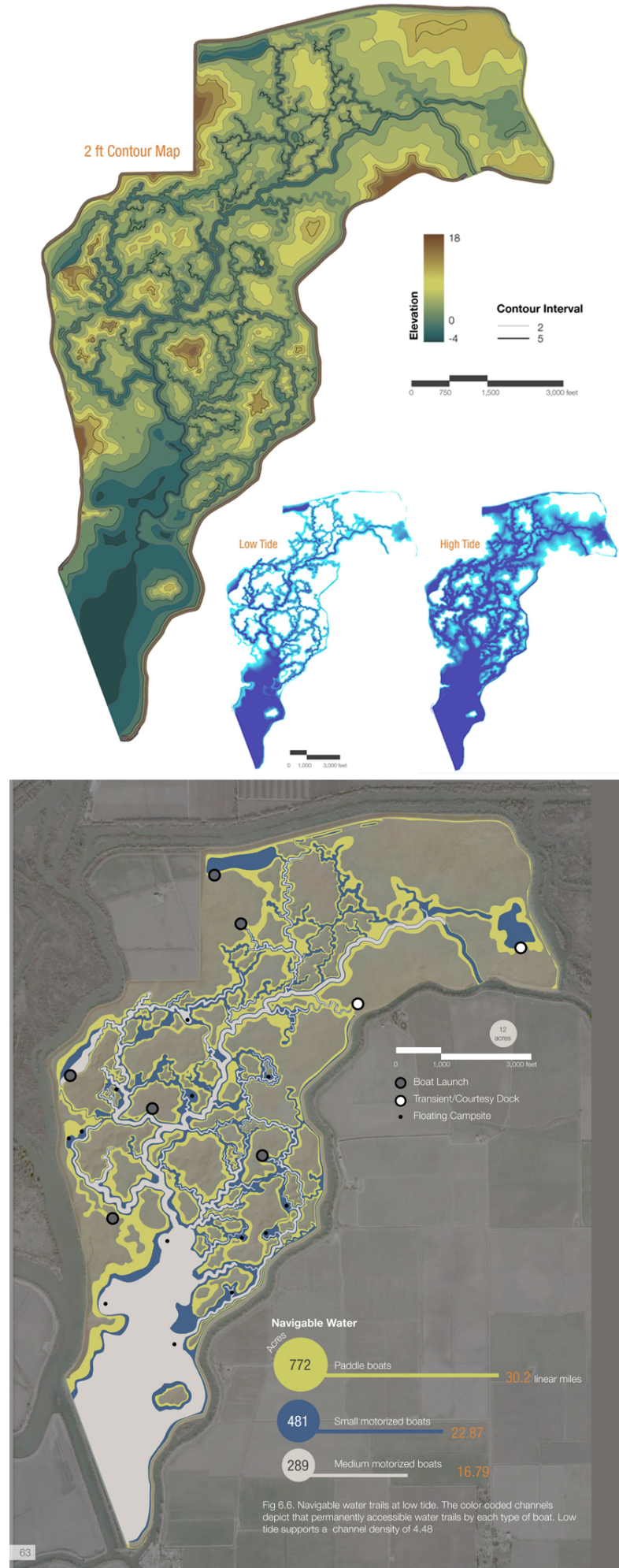

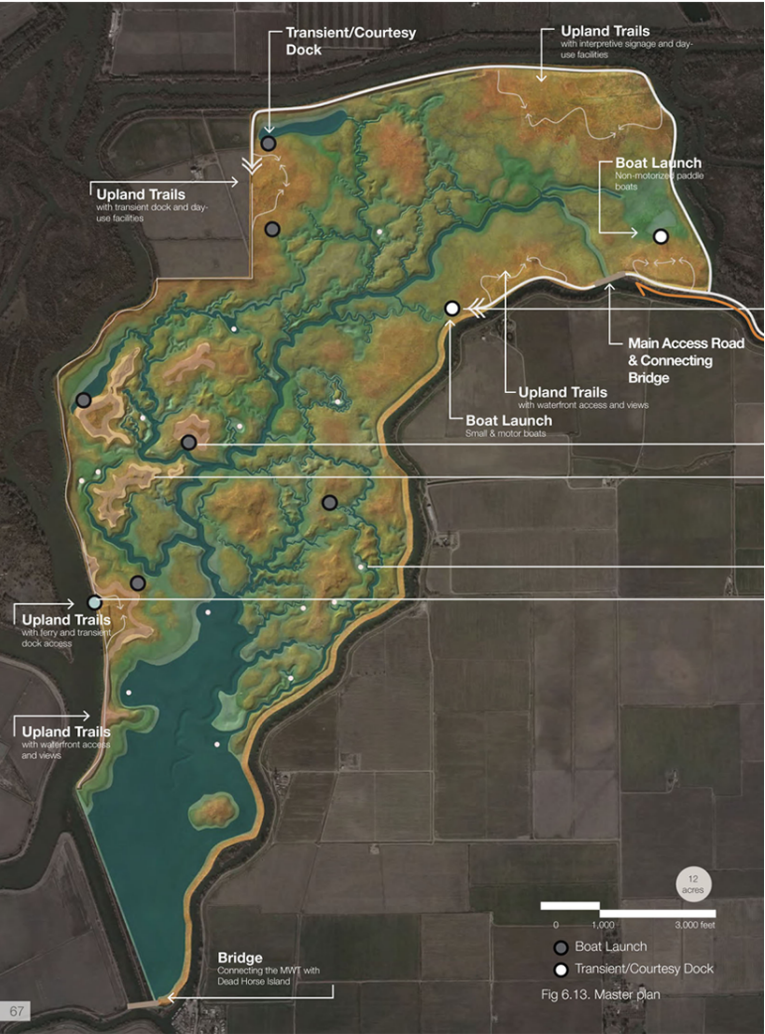

MASTER PLAח * DESIGח INTERUENTION Recreation Plan // Boating Trail

$$
\begin{aligned}
& \text { The variation in size and depth of the channels determines the form } \\
& \text { of recreation that can occur whthin each channel. The majorty of the } \\
& \text { ste is accessible by paddle boats, which require onlly a few inches of } \\
& \text { water. Meanwhile small and medium motor boats may only access } \\
& \text { specific islands and facilities, ensuring access for maintenance and }
\end{aligned}
$$
specific islands a
safety concerns.

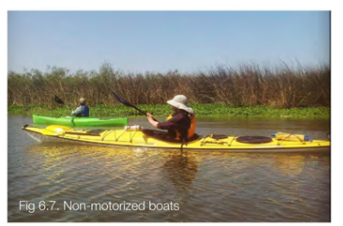

Non-motorized boats $(<16$ feet) Channel depth: less then 6 inches

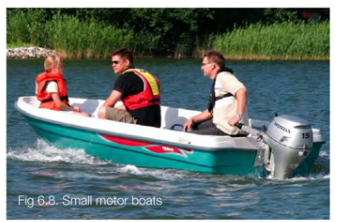

Small motor boats $16-26$ feet) Channel width: 20-30 feet

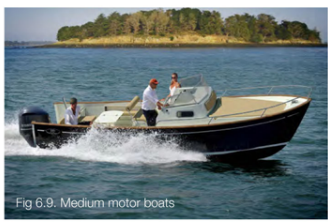

Medium motor boats $(>25$ teet Channel width $40-50$ feet
Channol dooth: 4 foet

Figure 8. "Navigating the Delta: The McCormack-Williamson Tract" (2014); Excerpts from a Planning and Design Project by UC Davis landscape architecture student Katie Herman, including ecological restoration concept (top) and overlay of recreation planning (bottom). Katie's project was developed in an advanced planning and design studio that expanded upon existing planning frameworks for the North Delta Flood Control Project, building a vision for incorporating aquatic and terrestrial recreation within the new ecological and hydrological conditions of an intentionally inundated and resculpted landscape. Based on the growing recreational demand in the Delta, this plan proposes implementing a network of boating trails, campsites, and interactive wayfinding media for the new waterways. The project was coordinated with and advised by representatives from the California Department of Water Resources, The Delta Conservancy and the Nature Conservancy. 
methods to expand these epistemologies are needed. High-level Delta planning reports have recently called out the need for scenario planning to allow for more integrative and long-term planning in the region (DSC, 2016; Luoma et al., 2015). Scenario planning is a disciplined and creative method for imagining potential future conditions. It can be considered a projective version of coevolutionary thinking, in which a chosen set of mutually affective trends and uncertainties are varied and played out across a set of tangible future scenarios (Peterson, Cumming, \& Carpenter, 2003; Schoemaker, 1995;
Shearer, 2005) (see Figures 9, 10 and 11). There are different varieties of scenario planning, and one of the most important distinctions is between exploratory and normative. Exploratory scenario planning is a method for imagining a plurality of futures that could potentially happen, rather than just those that "should happen", which is the basis of normative approaches. Exploratory planning can be particularly effective in opening up dialogue and collaboration where uncertainty and political conflict dominate, since they "compel participants to discuss and challenge their assumptions with others who hold

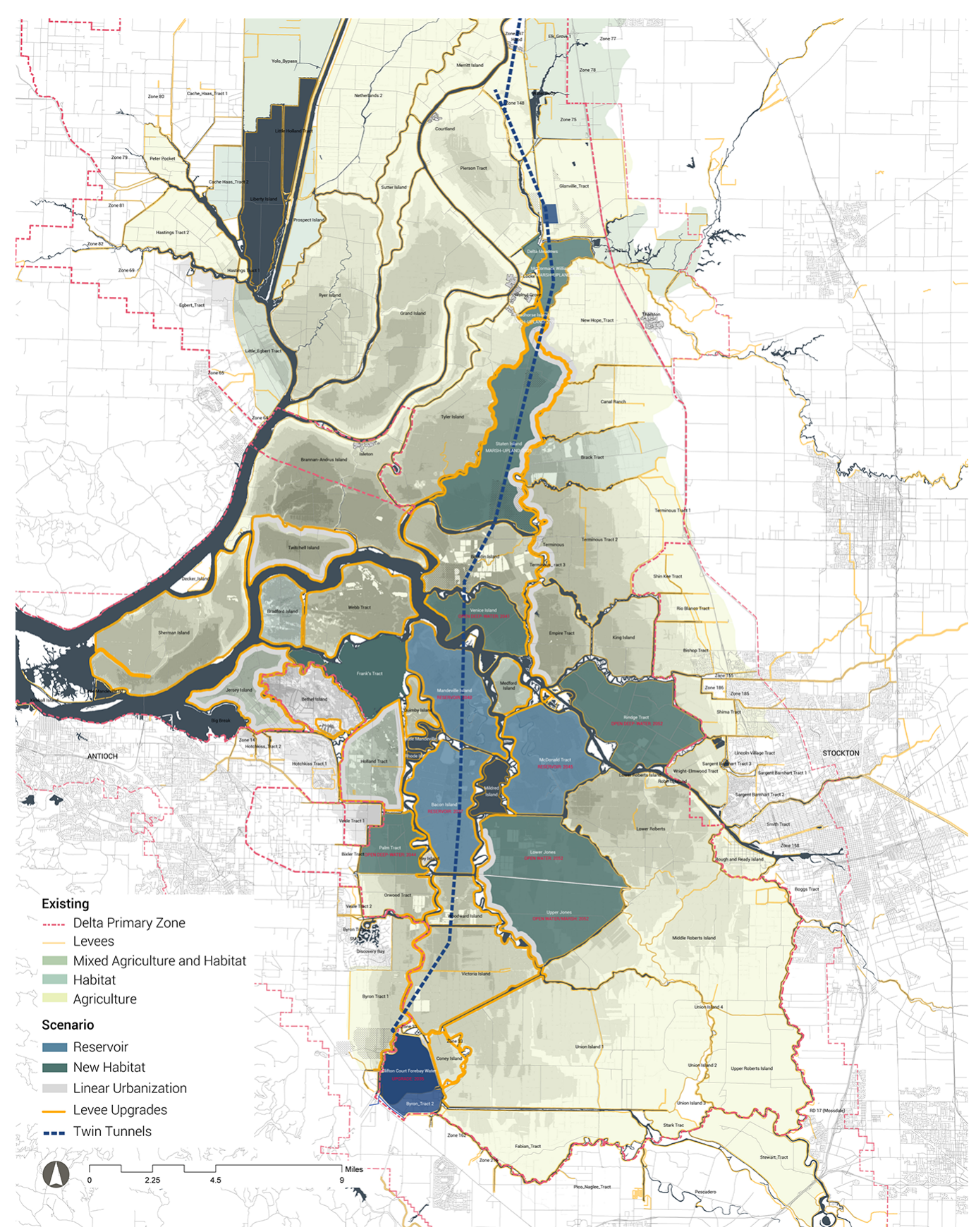

Figure 9. Delta-wide mapping of the Water Machine scenario (from Milligan \& Holmes, 2016). The Water Machine scenario explores the potential social, ecological and political implications of the California WaterFix, a plan which proposes to build twin 40' diameter tunnels that would convey water from the Sacramento River over a span of thirty miles, 150' below the ground surface of the Delta to export to cities and southern agricultural interests (from Milligan \& Holmes, 2016). 


\begin{tabular}{|c|c|c|c|c|c|}
\hline & Disasters & $\begin{array}{l}\text { Infrastructural } \\
\text { Investment }\end{array}$ & $\begin{array}{l}\text { Water } \\
\text { Exports }\end{array}$ & $\begin{array}{l}\text { Technological } \\
\text { Innovation }\end{array}$ & $\begin{array}{c}\text { Regional } \\
\text { Urbanization }\end{array}$ \\
\hline & $\begin{array}{r}\text { climate change } \\
\text { drought } \\
\text { temperature } \\
\text { sea level rise } \\
\text { species migration } \\
\text { species extinctions } \\
\text { seismicity } \\
\text { subsidence } \\
\text { salinity }\end{array}$ & $\begin{array}{r}\text { policy climates (national, state, } \\
\text { regional) } \\
\text { legal action/inaction } \\
\text { legislative action inacaction } \\
\text { maintenance } \\
\text { construction }\end{array}$ & $\begin{array}{r}\text { export demands } \\
\text { agricultural production } \\
\text { state population change } \\
\text { water allocations } \\
\text { water input volume } \\
\text { water input timing }\end{array}$ & $\begin{array}{r}\text { desalinization } \\
\text { levee improvements } \\
\text { landscape robotics } \\
\text { novel arriculture } \\
\text { flood-adaptable housing } \\
\text { market mechanisms (carbon, } \\
\text { environmental) }\end{array}$ & $\begin{array}{r}\text { population migration } \\
\text { immigration } \\
\text { speculation } \\
\text { urban form/distribution } \\
\text { high-speed rail }\end{array}$ \\
\hline $\begin{array}{l}\text { New } \\
\text { Deal }\end{array}$ & $\begin{array}{c}\text { Medium } \\
\text { (Early) }\end{array}$ & $\begin{array}{l}\text { Low } \\
\text { (Early) }\end{array}$ & Low & High & Low \\
\hline $\begin{array}{r}\text { Water } \\
\text { Machine }\end{array}$ & $\begin{array}{l}\text { Medium } \\
\text { (Late) }\end{array}$ & High & High & Medium & Medium \\
\hline $\begin{array}{l}\text { Augmented } \\
\text { Earthworks }\end{array}$ & Low & High & High & Medium & High \\
\hline $\begin{array}{r}\text { Feral } \\
\text { Bay }\end{array}$ & High & Low & Low & Low & $\begin{array}{l}\text { Medium } \\
\text { (Late) }\end{array}$ \\
\hline
\end{tabular}

Figure 10. Drivers (top) and four exploratory scenarios developed for the wicked ecologies project. The "water machine" scenario explores future possibilities in which significant investment is made in Delta infrastructure, with the primary goal of ensuring the stability of water exports. Climate change and earthquakes stress this water machine while land use fragments and diversifies, with some tracts surviving essentially intact while others are converted to novel uses ranging from open deep-water habitats to linear urbanization along super-levees (from Milligan \& Holmes, 2016).

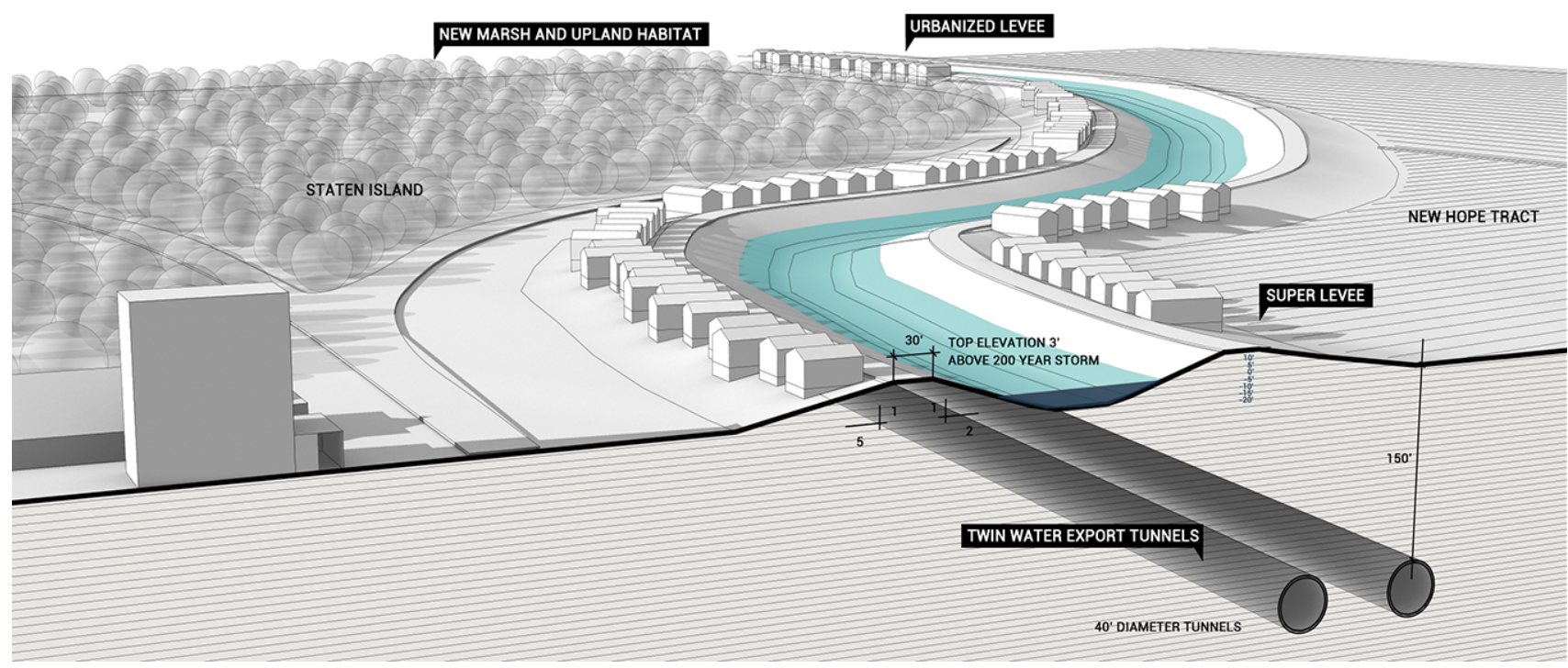

Figure 11. Spatially modeled section of the Water Machine scenario (WaterFix), showing urbanized super levees along the in-Delta water conveyance channels, restoration areas, and the subterranean tunnel infrastructure (from Milligan \& Holmes, 2016).

different beliefs" and thus serves as a "tool for integrating and synthesizing across epistemologies" (Bennett \& Zurek, 2006, pp. 276-277).

Envisioning how the Delta might evolve under very different conditions can permit planners and stakeholders "to inhabit multiple truths, nascent realities, contexts, and political perspectives" (Milligan \& Holmes, 2016), thus making participants "aware of the added value of possible creative combinations of actions and/or of the existing limitations in capabilities" (Boelens \& de Roo,
2016). ${ }^{9}$ In turn, this transdisciplinary learning space can open up new realizations and possibilities in future planning efforts.

\section{Conclusions}

The California Delta is a mascot for the challenges of Anthropocene landscapes: radically remade through massive works of engineering; ecologically rich and vital, yet novel, and largely destroyed; vulnerable and changing

\footnotetext{
${ }_{9}^{9}$ The science that informs such planning is trending towards the post-normal, with an emphasis on deliberation, values, plurality of legitimate perspectives, uncertainty, and the erosion of the monopoly of experts within collective decision-making (Funtowicz, Alier, Munda, \& Ravetz, 1999; Ravetz, 2005).
} 
faster than we can understand it due to what we have set in motion; and just to make things more complex, add the US and global economies' reliance on its infrastructural capacity to export fresh water. As restoration mandates attempt to reconcile some of these challenges and competing needs, the overlapping planning arenas and place-based factors we have identified will continue to influence restored and naturalized Delta landscapes and the people who live, work and play in them. This human-environment coevolution will occur whether or not it is explicitly considered in restoration planning, design and management discussions. Yet the qualities these landscapes will assume very much depends on whether or not their development is intentionally stewarded and in what manner. Our research intervention is just one interpretation and envisioning of many possible developmental trajectories the Delta might assume.

Based on past mistakes and the emergence of new approaches in the Delta, we see signs of recognition that planners, engineers, designers and scientists interact in complex and indeterminate networks, rather than clear modernist hierarchies (Gerrits \& Teisman, 2016). In turn, this recognition will require expanded epistemologies that can accommodate and plan for ecological and sociocultural values. We seek to advance a movement towards grounded, pluralistic and adaptive planning, focusing on rigorous experimentation and "incremental changes that are dictated by the possibilities that are specific to a certain time and location" (Gerrits \& Teisman, 2016). The dynamic and territorial challenges of the Delta demand that planners are humble in their aspirations, yet do not shy away from "impractical changes" (Luoma et al., 2015; Norgaard, 2013).

\section{Acknowledgments}

We would like to thank the many planners, scientists, researchers, land managers, public officials, Delta residents and many others who participated in our study, and those who helped to make the study possible. We would specifically like to thank the UC Davis Center for Watershed Sciences for their support.

\section{Conflict of Interests}

The authors declare no conflict of interests.

\section{References}

Bennett, E., \& Zurek, M. (2006). Integrating epistemologies through scenarios. In F. Berkes et al. (Eds.), Bridging scales and knowledge systems: Concepts and applications in ecosystem assessment (pp. 275-294). Washington, DC: Island Press.

Boelens, L., \& de Roo, G. (2016). Planning of undefined becoming: First encounters of planners beyond the plan. Planning Theory, 15(1), 42-67. doi:10.1177/ 1473095214542631
Bureau of Reclamation. (2011). Water and land recreation opportunity spectrum (WALROS). Denver, CO: U.S. Department of the Interior Bureau of Reclamation.

Brenner, N., \& Schmid, C. (2015). Towards a new epistemology of the urban? City, 19(2/3), 151-182. doi:10.1080/13604813.2015.1014712

Bryant, L. R. (2014). Onto-cartography: An ontology of machines and media. Edinburgh: Edinburgh University Press.

California Department of Parks and Recreation. (2011). Recreation proposal for the Sacramento-San Joaquin Delta. Retrieved from http://www.parks.ca.gov/ pages/795/files/delta\%20rec\%20proposal_08_02_ 11.pdf

California Department of Water Resources. (2010). North Delta flood control and ecosystem restoration project final environmental impact report. Sacramento, CA: DWR.

California Natural Resources Agency. (2017). California WaterFix. Retrieved from https://www.california waterfix.com

Castells, M. (2001). Space of flows, space of places: Materials for a theory of urbanism in the information age. In R. T. LeGates \& F. Stout (Eds.), The city reader. Abingdon and New York: Routledge.

Center for California Studies. (2015). Delta narrativesSaving the historical and cultural heritage of the Sacramento-San Joaquin Delta. Sacramento, CA: California State University. Retrieved from http://delta. blogs.ca.gov/files/2016/10/Delta_Narratives_Final_ Report.pdf.

Cloern, J. E., Knowles, N., Brown, L. R., Cayan, D., Dettinger, M. D., Morgan, T. L., .. . Jassby, A. D. (2011). Projected evolution of California's San Francisco BayDelta-River system in a century of climate change. Plos one, 6(9), e24465.

Corbin, J., \& Strauss, A. (2014). Basics of qualitative research: Techniques and procedures for developing grounded theory. Thousand Oaks, CA: SAGE Publications.

Cowen, D. (2014). The deadly life of logistics: Mapping violence in global trade. Minneapolis, MN: University of Minnesota Press.

Davis, B., Holmes, R., \& Milligan, B. (2015). Isthmus: On the Panama Canal expansion. Places Journal. Retrieved from https://placesjournal.org/article/ isthmus-panama-canal-expansion

Dettinger, M., Anderson, J., Anderson, M., Brown, L., Cayan, D., \& Maurer, E. (2016). Climate change and the Delta. San Francisco Estuary and Watershed Science, 14(3). Retrieved from http://www. escholarship.org/uc/item/2r71j15r

Deverel, S. J., Bachand, S., Brandenberg, S. J., Jones, C. E., Stewart, J. P., \& Zimmaro, P. (2016). Factors and processes affecting delta levee system vulnerability. San Francisco Estuary and Watershed Science, 14(4). Retrieved from http://www.escholarship.org/ 
uc/item/36t9s0mp

Deverel, S. J., \& Leighton, D. A. (2010). Historic, recent, and future subsidence, Sacramento-San Joaquin Delta, California, USA. San Francisco Estuary and Watershed Science, 8(2). Retrieved from https:// escholarship.org/uc/item/7xd4x0xw.pdf

Delta Vision Blue Ribbon Task Force. (2008, October 17). Delta vision strategic plan. Retrieved from http://deltavision.ca.gov/strategicplanningprocess/ staffdraft/delta_vision_strategic_plan_standard_re solution.pdf

Delta Independent Science Board. (2016). Improving adaptive management in the Sacramento-San Joaquin Delta. Sacramento, CA: DISB.

Delta Independent Science Board. (2017). Review of research on the Sacramento-San Joaquin Delta as an evolving place. Sacramento, CA: DISB.

Delta Protection Commission. (2012). Economic sustainability plan for the Sacramento-San Joaquin Delta. West Sacramento, CA: DPC. Retrieved from http://delta.blogs.ca.gov/files/2016/10/Final_ESP_w Appendices_2012.pdf

Delta Protection Commission. (2015). Vision 2030 strategic plan. West Sacramento, CA: DPC.

Delta Protection Commission. (2017). Delta national heritage area. West Sacramento, CA: DPC. Retrieved from http://delta.ca.gov/delta_heritage/delta_na tional_heritage_area

Delta Stewardship Council. (2013). The Delta plan. Sacramento, CA: DSC. Retrieved from http://delta council.ca.gov/delta-plan-0

Delta Stewardship Council. (2016). The Delta on fast forward-Thinking beyond the next crisis: Perspectives on the state of bay-delta science. Sacramento, CA: DSC.

Delta Stewardship Council. (2017). Delta levees investment strategy. Sacramento, CA: DSC. Retrieved from http://deltacouncil.ca.gov/delta-levees-investmentstrategy.

Drenthen, M. (2009). Ecological restoration and place attachment: Emplacing non-places? Environmental Values, 285-312.

Easterling, K. (2014). Extrastatecraft: The power of infrastructure space. New York: Verso Books.

Eliason, S. L. (2006). Factors influencing job satisfaction among state conservation officers. Policing: An International Journal of Police Strategies \& Management, 29(1), 6-18.

Funtowicz, S. O., Alier, J. M., Munda, G., \& Ravetz, J. R. (1999). Information tools for environmental policy under conditions of complexity. Luxembourg: Publications Office of the European Union. Retrieved from http://www.pedz.uni-mannheim.de/daten/edz-bn/ eua/00/envissue09.pdf

Gerrits, L. (2010). Public decision-making as coevolution. Emergence: Complexity and organization, 12(1), 19.

Gerrits, L., \& Teisman, G. (2012). Co-evolutionary planning processes. In G. de Roo, J. Hillier, \& J. Van Weze- mael (Eds.), Complexity and planning: Systems, assemblages and simulations (pp. 199-219). Farnham: Ashgate.

Grabowski, Z. J., Matsler, A. M., Thiel, C., McPhillips, L., Hum, R., Bradshaw, A., . . Redman, C. (2017). Infrastructures as socio-eco-technical systems: Five considerations for interdisciplinary dialogue. Journal of Infrastructure Systems, 23(4), 02517002.

Graham, S., \& Marvin, S. (2001). Splintering urbanism: Networked infrastructures, technological mobilities and the urban condition. UK: Psychology Press.

Gual, M. A., \& Norgaard, R. B. (2010). Bridging ecological and social systems coevolution: A review and proposal. Ecological Economics, 69(4), 707-717.

Hanak, E. (2015). Five things you need to know about water. The PPIC Blog. Retrieved from http://www. ppic.org/main/blog_detail.asp?i=1736

Helzer, J. (2015). Building communities in the Sacramento-San Joaquin Delta: Economics and ethnicity. Sacramento, CA: DPC.

Hobbs, J., Moyle, P. B., Fangue, N., \& Connon, R. E. (2017). Is extinction inevitable for Delta Smelt and Longfin Smelt? an opinion and recommendations for recovery. San Francisco Estuary and Watershed Science, 15(2). Retrieved from http://www. escholarship.org/uc/item/2k06n13x

Ingold, T. (1993). The temporality of the landscape. World Archaeology, 25(2), 152-174.

Kallis, G., Kiparsky, M., \& Norgaard, R. (2009). Collaborative governance and adaptive management: Lessons from California's CALFED Water Program. Environmental Science \& Policy, 12(6), 631-643.

Laćan, I., \& Resh, V. H. (2016). A case study in integrated management: Sacramento-San Joaquin Rivers and Delta of California, USA. Ecohydrology \& Hydrobiology, 16(4), 215-228.

Latour, B. (2004a). Why has critique run out of steam? From matters of fact to matters of concern. Critical Inquiry, 30(2), 225-248.

Latour, B. (2004b). Politics of nature. Cambridge, MA: Harvard University Press.

Latour, B. (2013). An inquiry into modes of existence. Cambridge, MA: Harvard University Press.

LeCavalier, J. (2016). The Rule of logistics: Walmart and the architecture of fulfillment. Minneapolis, MN: University of Minnesota Press.

Lund, J., Hanak, E., Fleenor, W., Bennett, W., \& Howitt, R. (2010). Comparing futures for the Sacramento-San Joaquin Delta (Vol. 3). Berkeley, CA: University of California Press.

Lund, J. R., \& Moyle, P. (2013). Adaptive management and science for the Delta ecosystem. San Francisco Estuary and Watershed Science, 11(3). Retrieved from http://escholarship.org/uc/item/1h57p2nb.pdf

Luoma, S. N., Dahm, C. N., Healey, M., \& Moore, J. N. (2015). Challenges facing the Sacramento-San Joaquin Delta: Complex, chaotic, or simply cantankerous? San Francisco Estuary and Watershed Science, 
13(3). doi:10.15447/sfews.2015v13iss3art7

Lyster, C. (2016). Learning from logistics: How networks change our cities. Basel: Birkhäuser.

Mees, H., Tempels, B., Crabbé, A., \& Boelens, L. (2016). Shifting public-private responsibilities in Flemish flood risk management. Towards a co-evolutionary approach. Land Use Policy, 57, 23-33.

Milligan, B. (2015). Landscape migration. Places Journal. Retrieved from https://placesjournal.org/article/ landscape-migration

Milligan, B., \& Holmes, R. (2016). Delta earthworks, wicked problems and speculative design scenarios. In Landscape Architecture as Necessity conference proceedings. University of Southern California, Los Angeles, USA.

Milligan, B., \& Kraus-Polk, A. (2016). Human use of restored and naturalized delta landscapes. Davis, CA: UC Davis.

Milligan, B., \& Kraus-Polk, A. (2017). Human use of restored and naturalized landscapes in the Delta. San Francisco Estuary and Watershed Science, 15.

Mitchell, S. D. (2009). Unsimple truths: Science, complexity, and policy. Chicago, IL: University of Chicago Press.

Mount, J., \& Twiss, R. (2005). Subsidence, sea level rise, and seismicity in the Sacramento-San Joaquin Delta. San Francisco Estuary and Watershed Science, 3(1). Retrieved from http://eprints.cdlib.org/uc/ item/4k44725p.pdf

Moyle, P., Bennett, W., Durand, J., Fleenor, W., Gray, B., Hanak, E., Lund, J., Mount Jr, J. (2012). Where the wild things aren't making the Delta a better place for native species. San Francisco, CA: Public Policy Institute of California.

Moyle, P., \& Lund, J. (2015, May 23). Delta ecosystem is in a constant state of change. Sacramento Bee. Retrieved from http://www.sacbee.com/opinion/ california-forum/article21621063.html.

Norgaard, R. B. (1984). Coevolutionary development potential. Land Economics, 60(2), 160-173.

Norgaard, R. B. (1988). Sustainable development: A coevolutionary view. Futures, 20(6), 606-620.

Norgaard, R. B. (1994). Development betrayed: The end of progress and a co-evolutionary revisioning of the future. Routledge. Taylor \& Francis.

Norgaard, R. B. (2013). The Econocene and the Delta. San Francisco Estuary and Watershed Science, 11(3). Retrieved from http://eprints.cdlib.org/uc/ item/4h98t2m0.pdf

Norgaard, R. B., \& Kallis, G. (2011). Coevolutionary contradictions: Prospects for a research programme on social and environmental change. Geografiska Annaler: Series B, Human Geography, 93(4), 289-300.

Norgaard, R. B., Kallis, G., \& Kiparsky, M. (2009). Collectively engaging complex socio-ecological systems: Re-envisioning science, governance, and the California Delta. Environmental Science \& Policy, 12(6), 644-652.
Ogden, L. (2008). The Everglades ecosystem and the politics of nature. American Anthropologist, 110(1), 21-32.

Ogden, L. A. (2011). Swamplife: People, gators, and mangroves entangled in the Everglades. Minneapolis, MN: University of Minnesota Press.

Peterson, G. D., Cumming, G. S., \& Carpenter, S. R. (2003). Scenario planning: A tool for conservation in an uncertain world. Conservation Biology, 17(2), 358-366.

Pierce, P. (1988). A geoarchaeological analysis of the prehistoric Sacramento-San Joaquin Delta, California (Master's Thesis). University of California, Davis, USA. Retrieved from http://www.calwater. ca.gov/Admin_Record/C-073579.pdf

Ravetz, J. (2005). The post-normal sciences of precaution. Water Science and Technology, 52(6), 11-17.

Reed, J., Deakin, L., \& Sunderland, T. (2015). What are 'integrated landscape approaches' and how effectively have they been implemented in the tropics: A systematic map protocol. Environmental Evidence, 4(1), 2.

Renaud, F. G., Syvitski, J. P., Sebesvari, Z., Werners, S. E., Kremer, H., Kuenzer, C., Ramachandran, R., Ad, J. Friedrich, J. (2013). Tipping from the Holocene to the Anthropocene: How threatened are major world deltas? Current Opinion in Environmental Sustainability, 5(6), 644-654.

Rittel, H. W., \& Webber, M. M. (1973). Dilemmas in a general theory of planning. Policy Sciences, 4(2), 155-169.

Robinson, A. H., Safran, S. M., Beagle, J., Grossinger, R. M., Grenier, J. L., \& Askevold, R. A. (2014). A delta transformed: Ecological functions, spatial metrics, and landscape change in the Sacramento-San Joaquin Delta (SFEI Contribution No. 729). Richmond, CA: San Francisco Estuary Institute \& Aquatic Science Center.

Rosenzweig, M. L. (2003). Reconciliation ecology and the future of species diversity. Oryx, 37(2), 194-205.

Rydin, Y. (2014). The challenges of the "material turn" for planning studies. Planning Theory \& Practice, 15(4), 590-595.

Sarewitz, D. (2004). How science makes environmental controversies worse. Environmental Science \& Policy, 7(5), 385-403.

Schipper, D., \& Gerrits, L. M. (2014). The emergence of metropolitan governance: A coevolutionary analysis of the life-and-death cycles of metropolitan governance in the Amsterdam metropolitan region. Complexity, Governance \& Networks, 1(2), 57-78.

Schoemaker, P. J. (1995). Scenario planning: A tool for strategic thinking. MIT Sloan Management Review, $36(2), 25$.

Shearer, A. W. (2005). Approaching scenario-based studies: Three perceptions about the future and considerations for landscape planning. Environment and Planning B: Planning and Design, 32(1), 67-87.

Shigley, P. (2012). The devil is in the Delta. Planning Magazine. Retrieved from https://www.planning.org/ 
planning/2012/jan/waterwarriorsside1.htm

Smith, N. (2013). Sense of place impacts for rural residents in the Sacramento-San Joaquin River Delta (Master's Thesis). Duke University, Durham, USA. Retrieved from http://dukespace.lib.duke.edu/dspace/ handle/10161/6910

Suddeth Grimm, R., \& Lund, J. R. (2016). Multi-purpose optimization for reconciliation ecology on an engineered floodplain: Yolo bypass, California. San Francisco Estuary and Watershed Science, 14(1). Retrieved from http://escholarship.org/uc/item/28 j7rohd

Tempels, B., \& Hartmann, T. (2014). A co-evolving frontier between land and water: Dilemmas of flexibility versus robustness in flood risk management. Water International, 39(6), 872-883.

Tessler, Z. D., Vörösmarty, C. J., Grossberg, M., Gladkova, I., Aizenman, H., Syvitski, J. P. M., \& FoufoulaGeorgiou, E. (2015). Profiling risk and sustainability in coastal deltas of the world. Science, 349(6248), 638-643.

Thompson, J. (1957). The settlement geography of the Sacramento-San Joaquin Delta, California (PhD Thesis). Stanford University, USA. Retrieved from https://watershed.ucdavis.edu/pdf/thompson- dissertation\%20small.pdf

van Staveren, M., \& van Tatenhove, J. (2016). Hydraulic engineering in the social-ecological delta: Understanding the interplay between social, ecological, and technological systems in the Dutch delta by means of "Delta trajectories". Ecology and Society, 21(1), 8.

Vörösmarty, C. J., Syvitski, J., Day, J., de Sherbinin, A., Giosan, L., \& Paola, C. (2009). Battling to save the world's river deltas. Bulletin of the Atomic Scientists, 65(2), 31-43.

Waldheim, C., \& Berger, A. (2008). Logistics landscape. Landscape Journal, 27(2), 219-246.

Wiens, J., Grenier, L., Grossinger, R., \& Healey, M. (2016). The Delta as changing landscapes. San Francisco Estuary and Watershed Science, 14(2). Retrieved from https://escholarship.org/uc/item/7xg4j201.pdf

Wolff, J. (2003). Delta primer: A field guide to the California Delta. Richmond, CA: William Stout.

Worster, D. (1982). Hydraulic society in California: An ecological interpretation. Agricultural History, 56(3), 503-515.

Worster, D. (1985). Rivers of empire: Water, aridity, and the growth of the American West. Oxford: Oxford University Press.

\section{About the Authors}

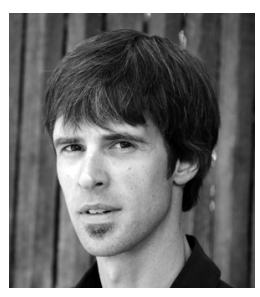

Brett Milligan is Professor of Landscape Architecture and Environmental Design at the University of California, Davis. He is a founding member of the Dredge Research Collaborative and director of Metamorphic Landscapes. His research focuses on infrastructural landscapes, urbanized deltas and the dynamic interface between land and water, using integrative methods to meld ecological and other performance metrics with technology, aesthetics and socio-cultural values.

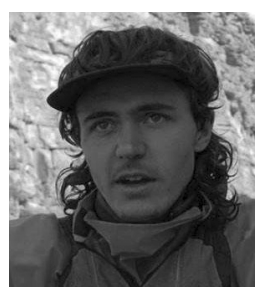

Alejo Kraus-Polk is a PhD student in the Geography Graduate Group at the University of California, Davis. Growing up in Berkeley, California, Alejo's first exposure to the Delta was as an intern at the Delta Stewardship Council and researcher with American Rivers, where he began his ongoing explorations into the reconciliation of ecosystem restoration with existing and new types of human use. Alejo received his B.S. in International Agriculture and Rural Development from Cornell University. 